\title{
Growth Promoting Rhizospheric and Endophytic Bacteria from Curcuma longa L. as Biocontrol Agents against Rhizome Rot and Leaf Blight Diseases
}

\author{
G. Vinayarani and H. S. Prakash (D)* \\ Department of Studies in Biotechnology, University of Mysore, Manasagangotri, Mysuru 570006, India \\ (Received on November 2, 2017; Revised on February 19, 2018; Accepted on March 7, 2018)
}

Plant growth promoting rhizobacteria and endophytic bacteria were isolated from different varieties of turmeric (Curcuma longa L.) from South India. Totally 50 strains representing, 30 PGPR and 20 endophytic bacteria were identified based on biochemical assays and $16 \mathrm{~S}$ rDNA sequence analysis. The isolates were screened for antagonistic activity against Pythium aphanidermatum (Edson) Fitzp., and Rhizoctonia solani Kuhn., causing rhizome rot and leaf blight diseases in turmeric, by dual culture and liquid culture assays. Results revealed that only five isolates of PGPR and four endophytic bacteria showed more than $70 \%$ suppression of test pathogens in both assays. The SEM studies of interaction zone showed significant ultrastructural changes of the hyphae like shriveling, breakage and desication of the pathogens by PGPR B. cereus (RBacDOB-S24) and endophyte $P$. aeruginosa (BacDOB-E19). Selected isolates showed multiple Plant growth promoting traits. The rhizome bacterization followed by soil application of B. cereus (RBacDOB-S24) showed lowest Percent Disease Incidence (PDI) of rhizome rot and leaf blight, $16.4 \%$ and $15.5 \%$ respectively. Similarly, $P$. aeruginosa (BacDOB-E19) recorded PDI of rhizome rot $(17.5 \%)$ and leaf blight $(17.7 \%)$. The treatment of these promising isolates exhibited significant increase in plant height and fresh rhizome yield/plant in comparison with untreated control under greenhouse condition.

\footnotetext{
*Corresponding author.

Phone) 0821-2419877, FAX) 0821-2414450

ORCID

http://orcid.org/0000-0002-9973-7939

E-mail) hasriprakash@gmail.com,hsp@appbot.uni-mysore.ac.in (c) This is an Open Access article distributed under the terms of the Creative Commons Attribution Non-Commercial License (http:/ creativecommons.org/licenses/by-nc/4.0) which permits unrestricted noncommercial use, distribution, and reproduction in any medium, provided the original work is properly cited.
}

Articles can be freely viewed online at www.ppjonline.org.
Thereby, these isolates can be exploited as a potential biocontrol agent for suppressing rhizome rot and leaf blight diseases in turmeric.

Keywords : antagonism, biocontrol, growth promotion, $P$. aphanidermatum, $R$. solani

Handling Associate Editor : Sang, Mee Kyung

Turmeric (Curcuma longa L., Family-Zingeberaceae) is a rhizomatous perennial herb cultivated in Indian sub-continent and middle East countries. Dried rhizomes are used as condiment, dye, drug and for cosmetics. India is the leading producer of turmeric in the world and contributes about $75-80 \%$ of the world production followed by China, Myanmar, Nigeria and Bangladesh. The main turmeric producing states in India are Andhra Pradesh, Tamil Nadu, Orissa, West Bengal, Maharashtra, Karnataka and Kerala (Thiripurasundari and Selvarani, 2014). The fungus $P$. aphanidermatum and $R$. solani cause rhizome rot and leaf blight diseases in turmeric plants and reduce commercial value (Park, 1934; Roy, 1992). It has been noted that chemical fungicides like Ridomil, Metalaxyl, Carbendazim (0.1\%) and Mancozeb $(0.25 \%)$ were commonly used to manage rhizome rot and leaf blight diseases (Muthukumar et al., 2011; Rathaiah, 1982). Use of chemical fungicides is of public concern as it causes various human health problems and also pathogens build resisitance against fungicides. The need for adopting environment friendly disease control measures such as biological control strategies are emphasized presently (Hallmann et al., 2009). An alternative to chemical fungicides for the management of plant diseases is the use of soil borne, non-pathogenic rhizospheric or endophytic bacteria.

Plant growth promoting rhizobacteria (PGPR) may induce plant growth promotion by direct or indirect modes of action (Kloeppe et al., 1999). Common PGPR include the 
strains of Bacillus, Rhizobium, Acinetobacter, Alcaligenes, Azotobacter, Arthrobacter, Enterobacter, Pseudomonas, Serratia and Burkholderia (Kloepper et al., 1989). Earlier reports emphasizes the biocontrol potential of PGPRs in agriculture along with growth promotion (Siddiqui, 2005). The PGPR Bacillus subtilis and Burkholderia cepacia significantly decreased ginger rhizome rot incidence along with increase in yield was reported (Shanmugam et al., 2013).

Endophytes are ubiquitous and have been found in all species of plants. In general, Endophytes could produce different plant hormones to enhance the growth of the host plants (Waqas et al., 2012). Bacterial endophytes colonize the internal tissues of the plant showing no negative effect on their host (Schulz et al., 2006). In comparison to PGPR, endophytes showed better adaptations against biotic and abiotic stresses, that leads to enhanced plant growth (Pillay and Nowak, 1997). Many endophytes constitute the common rhizospheric bacteria (Burkholderia, Pseudomonas and Bacillus) that produce various secondary metabolites, volatile compounds and antibiotics to counter the deleterious effect of pathogens through mechanisms similar to that of PGPR (Lodewyckx et al., 2002).

Endophytic bacteria are promising biocontrol agents as they occupy internal living tissues of plants and due to close proximity to plant pathogens. Endophytic bacteria were used as BCA's against plant pathogenic fungi such as R. solani, Pythium sp., Alternaria alternata, Fusarium sp., Botrytis cinerea, Verticillium dahlia, Penicillium digitatum, Sclerotinkia sclerotiorum, B. fabae, Colletotrichum gloeosporioides (Cao et al., 2005). Some endophytic bacteria colonize an ecological niche which makes them suitable as biocontrol agents (Berg et al., 2005).

Direct mode of action of PGPR includes fixation of atmospheric nitrogen, solubalization of minerals, production of phytohormones and enzymes in plants (Bashan and deBhashan, 2005) whereas indirect mode includes production of siderophores (Kuffner et al., 2008), production of antibiotics, lytic enzymes such as $\beta-(1,3)$ glucanase and chitinase, antifungal metabolities that cause lysis of fungal cell wall, competition and inhibition of phytopathogens along with induction of systemic resistance (Ahmad et al., 2008; Compant et al., 2005). Similarly, endophytes reduces the bacterial, fungal, and viral diseases (Berg and Hallmann, 2006; Sturz et al., 2000) by producing siderophores (Lodewyckx et al., 2002) and lytic enzymes (Chernin and Chet, 2002). The endophyes also enhance the plant growth by production of Indole acetic acid (Rana et al., 2011) and Phosphate solubilization activity (Verma et al., 2001; Wakelin et al., 2004).
Several reports are available on the isolation of PGPR and endophytes, and their effects on growth and yield of crops. The biocontrol agents like $T$. viride, $P$. chlororaphis and B. subtilis were used for suppression of rhizome rot of turmeric (Kavitha et al., 2012; Ramarethinam and Rajagopal, 1999). Nevertheless, very little information is available on the effect of native multi trait PGPR and endophyes on growth promotion and biocontrol of rhizome and leaf blight diseases of turmeric. This study was taken up to profile the rhizobacteria and endophytic bacteria associated with turmeric and to evaluate their antagonistic activities, biocontrol potentialand plant growth promotion both in vitro and in vivo conditions against $P$. aphanidermatum and $R$. solani pathogens which cause rhizome rot and leaf blight diseases of turmeric respectively.

\section{Materials and Methods}

Sampling. Soil samples were collected from four different states of South India viz., Karnataka, Kerala, Tamilnadu and Andhra Pradesh. Samples were collected from top five $\mathrm{cm}$ of soil around healthy turmeric plants adhering to the roots. Collected soil samples (30 nos) were sealed in sterile polythene bags and transferred to ice box for transport. For endophyte isolation, healthy turmeric rhizomes (20 nos) were also collected from the above said regions in polythene bags, labeled and stored in refrigerator at $4^{\circ} \mathrm{C}$ in laboratory and processed within $48 \mathrm{~h}$ of collection.

Isolation of bacteria from rhizosphere. Ten gram of soil sample was placed in $95 \mathrm{ml}$ sterile water $\left(10^{-1}\right)$ and shaken for $10 \mathrm{~min}$. One (1.0) $\mathrm{ml}$ of this suspension was transferred into a $9 \mathrm{ml}$ blank $\left(10^{-2}\right)$ and serially diluted up to $10^{-10}$. About $0.1 \mathrm{ml}$ of each dilution from $10^{-8}$ to $10^{-10}$ series was added on Nutrient Agar (NA) medium and incubated at $37^{\circ} \mathrm{C}$ for 2-3 days. Morphologically distinct bacterial colonies were isolated and subcultured on NA medium, strains were temporarily cryopreserved at $-20{ }^{\circ} \mathrm{C}$ in $40 \%$ glycerol for further studies.

Isolation of endophytic bacteria from rhizomes. The collected rhizomes were thoroughly washed in running tap water to remove soil particles adhered followed by dipping in phosphate buffer (per L:6.33 g of $\mathrm{NaH}_{2} \mathrm{PO}_{4} ; 16.5 \mathrm{~g}$ of $\mathrm{Na}_{2} \mathrm{HPO}_{4} \cdot 7 \mathrm{H}_{2} \mathrm{O} ; 200 \mathrm{ml}$ Tween 40 ). Distilled water was used to remove foam of Tween 40. Rhizomes were further sterilized by sequential immersion in 70\% ethanol for 2 min and in $3.5 \%$ sodium hypochloride for $3 \mathrm{~min}$ and then rinsed several times in sterile distilled water to remove surface sterilization agents. One gram of rhizome was ground 
in a sterile mortar and pestle with phosphate buffered saline (PBS) and the solution was made up to $10 \mathrm{ml}$. Serial dilutions from $10^{-1}$ to $10^{-4}$ were prepared and $0.1 \mathrm{ml}$ of aliquots were spread onto NA medium amended with nystatin (50 $\mathrm{mg} \mathrm{ml}^{-1}$; Sigma Aldrich, Bengaluru, India) in triplicates under laminar air flow to avoid external contamination and the plates were incubated for 7 days at $37^{\circ} \mathrm{C}$. To verify the efficacy of surface sterilization of the rhizomes, $100 \mu \mathrm{l}$ of the last rinse was added on NA medium and incubated. Morphologically distinct bacterial colonies were selected and pure cultures were preserved in $40 \%(\mathrm{v} / \mathrm{v})$ glycerol solution at $-20^{\circ} \mathrm{C}$.

Pathogens. Virulent isolates of $P$. aphanidermatum (Accession No. KT315583) and R. solani (Accession No. KT366922) isolated from naturally infected turmeric rhizomes and leaves were obtained from the culture repository of the host Institute Department of Studies in Biotechnology, University of Mysore, Mysuru, India. Actively growing hyphae were successively transferred to the new PDA medium and the cultures were maintained on slants and stored at $4^{\circ} \mathrm{C}$.

Characterization of rhizospheric and endophytic bacterial strains. The colony morphology, size, shape, colour and growth pattern of all the bacterial isolates was noted. Biochemical tests viz., Methyl red test, Voges-Proskauer test, Citrate test, Presence of oxidase and catalase, succinic acid, starch hydrolysis, ammonia production, casein hydrolysis were conducted to characterize the isolated bacterial strains (Cappuccino and Sherman, 1992). The Gram's reaction was performed as per standard procedures (Holt et al., 1994). The motility of the bacteria was checked using hanging drop method and for the $\mathrm{KOH}$ solubility test, a loop full of bacterial strain was mixed with $3 \% \mathrm{KOH}$ solution on a clean glass slide for $1 \mathrm{~min}$ and observed for formation of a thread like mass. The isolates were grouped based on the results of phenotypic and biochemical characteristics.

For molecular characterization, DNA extraction was done using HipurA Bacterial DNA Purifiation kit of Himedia. DNA was quantified by NanoDrop spectrophotometer (2000C, Thermo Scientific, Tokyo, Japan) and the quality was checked based on absorbance ratio $260 / 280$. The integrity of the DNA was assayed by gel electrophoresis using $0.7 \%$ agarose gel. The DNA was amplified using universal primer pair of $16 \mathrm{~S}$ rDNA, Forward $16 \mathrm{~S}$ rDNA F 5'-CCAGACTCCTACGGGAGGCAGC-3' and reverse 5'-GCTGACGAGAGCCATGCAGCACC-3' (Sigma Aldrich, Bengaluru, India). The PCR reaction was per- formed in $50 \mu \mathrm{l}$ final reaction volume containing $5 \mu \mathrm{l}$ of 10X PCR buffer, $8 \mu$ l of $25 \mathrm{mM} \mathrm{MgCl} 2,2.5 \mu$ of $1.25 \mathrm{mM}$ dNTP, $0.2 \mu \mathrm{l}$ of each primer $(20 \mu \mathrm{M}), 100 \mathrm{ng}$ of DNA and

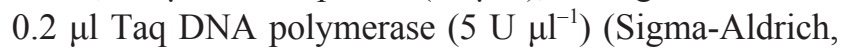
Bengaluru, India) in a thermal cycler (Bio-Rad, CA, USA) programmed for initial denaturation at $94^{\circ} \mathrm{C}$ for $5 \mathrm{~min}$, followed by 35 cycles of denaturation at $94^{\circ} \mathrm{C}$ for $45 \mathrm{~s}$, primer annealing at $56^{\circ} \mathrm{C}$ for $45 \mathrm{~s}$, extension at $72^{\circ} \mathrm{C}$ for $2 \mathrm{~min}$. At the end of the amplification reaction, a final extension step was achieved at $72^{\circ} \mathrm{C}$ for $10 \mathrm{~min}$. Ten microliters of the PCR products from each PCR reaction were electrophoresed on $1 \%$ agarose gel containing $5 \mathrm{mg} \mathrm{ml}^{-1}$ of ethidium bromide in a 1XTBE (PH 8.4) along with 100 bp molecular ladder (Sigma-Aldrich, Bengaluru, India) to estimate the size of the PCR products. The electrophoresis was carried out using 100 Volts. The gel was visualized and photographed using Gel Documentation system (Gel Doc 2000, Bio-Rad, CA, USA).

The amplified products were sequenced at Chromous Biotech. Pvt. Ltd, Bengaluru, India. The sequences obtained were blasted using the nucleotide BLAST search at the database of National Center for Biotechnology Information (NCBI, website: http://www.ncbi.nlm.nih.gov). The analysed sequences were submitted to Genbank (NCBI) and accession numbers obtained. Highly homologous sequences were aligned using Clustal-W algorithm (Thompson et al., 1994) and neighbor joining trees were generated by Molecular Evolutionary Genetics Analysis (MEGA) version 6.06 software with 1000 bootstrap replications (Tamura et al., 2011).

In vitro screening of rhizospheric and endophytic bacterial isolates for antagonism against $P$. aphanidermatum and $R$. solani

Antifungal activity in Dual culture method: All rhizospheric and endophytic bacterial isolates were screened for their antagonism in dual culture assays. The pathogen was inoculated in the middle of the petriplate containing PDA medium and bacteria were streaked $3 \mathrm{~cm}$ away on either sides of the pathogen and incubated at $28^{\circ} \mathrm{C}$ for 3 days. The petriplate inoculated with pathogen alone in the absence of antagonist served as control and the experiment was done in triplicates. The radial growth of fungal mycelium on each plate was measured and the percent inhibition of growth over control (absence of antagonists) was determined using the formula:

Inhibition of mycella growth $(\%)=\frac{X-Y}{X} \times 100$ 
Where, $X=$ mycelia growth of pathogen in absence of antagonists, $\mathrm{Y}=$ mycelia growth of pathogen in presence of antagonists

In the vicinity of bacterial colonies the morphology of hyphae of pathogens $P$. aphanidermatum and $R$. solani from PDA plates were observed under scanning electron microscope (SEM). The hyphal samples of pathogens were excised and fixed in $2.5 \%$ glutaraldehyde at $4^{\circ} \mathrm{C}$ for $2 \mathrm{~h}$ followed by washing in phosphate buffered saline (PBS) for 4 times, later dehydrated in a graded ethanol series $(70 \%$, $80 \%, 90 \%$, and $100 \%$ ) ten min each and air dried. It was then coated with gold in a POLARON, AU/PD sputter and scanned in SEM, S-3400N model (Hitachi, Tokyo, Japan) at $5.00 \mathrm{kV}$ and the abnormalities in the fungal hyphae were recorded (Minaxi and Saxena, 2010).

Antifungal activity in liquid culture: Dual liquid culture method was used to test the antifungal activity in potato dextrose broth (PDB). Bacterial isolates that showed more than $70 \%$ antagonism in dual culture plates were selected (Table 1). $100 \mathrm{ml}$ of PDB was sterilized in $250 \mathrm{ml}$ conical flask and inoculated with $5 \times 5 \mathrm{~mm}$ disc of pathogenic fungal mycelia and $1 \mathrm{ml}$ of bacterial culture (OD 0.25 at $590 \mathrm{~nm}$ ). It was incubated at $28 \pm 2^{\circ} \mathrm{C}$ for five days at 100 $\mathrm{rpm}$. Dry weight of the fungal culture grown with bacterial strains and control (without bacterial strains) were recorded and differences were calculated according to Broekaert et al. (1990) and percent inhibition was calculated.

Plant growth promoting (PGP) traits of rhizospheric and endophytic bacterial isolates. In in vitro study for antagonism only five rhizospheric and four endophytic bacteria showed more than $70 \%$ inhibition against pathogens (Table 1,2). These isolates were tested for their plant growth promoting traits. For Indole acetic acid (IAA) production test, each isolate was inoculated to the sterile 15 $\mathrm{ml}$ Nutrient broth (NB) amended with L-tryptophan in test tubes and incubated at $28^{\circ} \mathrm{C}$ for $72 \mathrm{~h}$ in the dark (Gordon and Weber, 1951). Subsequently, $2 \mathrm{ml}$ of this broth was centrifuged at 12,000 $\mathrm{g}$ for $10 \mathrm{~min}$, followed by addition of $4 \mathrm{ml}$ of Salkawaski reagent (Loper and Schroth, 1986) to the $1 \mathrm{ml}$ of supernatant. The tubes were incubated at $37^{\circ} \mathrm{C}$ in the dark for $1 \mathrm{~h}$. Development of a pink/red color in the medium indicated IAA production by the organisms.

Production of Hydrogen Cyanide (HCN) was determined in Nutrient agar (NA) supplemented with $4.4 \mathrm{~g} / \mathrm{l}^{-1}$ of glycine (Lorck, 1948). The slant cultures were streaked on agar and Whatman No.1 filter paper strips dipped in $0.5 \%$ picric acid in $2 \%$ sodium carbonate solution were inserted from the top of each test tube, sealed with parafilm and incubated at $30^{\circ} \mathrm{C}$ for 4 days. A change of colour to brown or reddish-brown was recorded as positive $(+)$ reaction.

Siderophore production of rhizospheric and endophytic bacteria was determined as described by Schwyn and Neilands (1987) using Chrome Azurol S (CAS) agar medium. The bacteria were spot inoculated and incubated at $30^{\circ} \mathrm{C}$ for 3-5 days. Development of yellow-orange halos around the colonies on CAS agar was considered as a positive result.

Phosphate solubalization ability of the strains was detected by spotting them on the Pikovskaya medium containing tricalcium phosphate and incubated at $28 \pm 2{ }^{\circ} \mathrm{C}$ for 2-3 days. Development of clear halo zone around the strains indicated positive result for phosphate solubalization (Pikovskaya, 1948).

Production of hydrolytic enzymes. Production of cell wall degrading enzymes such as protease and cellulase is a common mechanism used by bacteria to inhibit the growth of pathogenic microorganisms. For determining protease production one loop full of bacterial strains was streaked on skimmed milk agar plate (skimmed milk-100 g, peptone-5 $\mathrm{g}$, agar-15 g and distilled water $1000 \mathrm{ml}$ ). After $48 \mathrm{~h}$ of incubation at $28^{\circ} \mathrm{C}$, the development of clear zone around the streak was considered as a positive result. To determine celulolytic activity, carboxymethyl cellulose (CMC) was used in basal medium $\left(\mathrm{NaNO}_{3}-1 \mathrm{~g}, \mathrm{KCl}-1 \mathrm{~g}, \mathrm{~K}_{2} \mathrm{HPO}_{4}-1\right.$ $\mathrm{g}, \mathrm{MgSO}_{4^{-}} 0.5 \mathrm{~g}$, yeast extract- $0.5 \mathrm{~g}$, agar- $15 \mathrm{~g}$, distilled water $1000 \mathrm{ml}$ ). The bacteria was streaked on the medium and incubated at $28^{\circ} \mathrm{C}$ for 3 days. The plates were flooded with $0.01 \%$ congo red solution for $15 \mathrm{~min}$ and destained using $1 \% \mathrm{NaCl}$ solution for $5 \mathrm{~min}$. A clear zone indicated the degradation of $\mathrm{CMC}$ and the bacteria was positive for cellulase production (Cappuccino and Sherman, 1992).

Evaluation of rhizospheric and endophytic bacteria for growth promotion and disease suppression in green house. our promising bacterial isolates two each from rhizopheric PGPR isolates viz., $P$. putida RBacDOB-S21, $B$. cereus RBacDOB-S24 and endophytic bacteria $P$. aeruginosa BacDOB-E19, Enterobacter sp. BacDOB-E21were selected for green house studies based on in vitro antagonism studies and PGP traits. Two sets of experiments were performed to analyze the efficacy of the bacterial isolates in controlling the rhizome rot and leaf blight diseases of turmeric under green house condition by using turmeric cultivar 'Erode local' (susceptible). Four replications were maintained for each treatment and each replication consisted of 5 earthen pots ( $20 \mathrm{~cm}$ diameter) in a completely randomized design (CRD) in a green house. The experiment was repeated twice. The talc-based formulation of the rhizospheric and endophytic bacterial isolates was 
Table 1. Molecular identification of rhizospheric bacteria isolated from turmeric using 16S rDNA sequences and their antagonistic effect on the pathogenic fungus Pythium aphanidermatum and Rhizoctonia solani

\begin{tabular}{|c|c|c|c|c|c|c|c|c|}
\hline $\begin{array}{l}\text { Sl } \\
\text { No }\end{array}$ & Geographical loca & $\begin{array}{l}\text { Variety of } \\
\text { turmeric }\end{array}$ & $\begin{array}{c}\text { Rhizospheric } \\
\text { bacterial isolate } \\
\text { (PGPR) }\end{array}$ & $\begin{array}{c}\text { Closest } \\
\text { related species }\end{array}$ & $\begin{array}{c}\% \\
\text { Identity }\end{array}$ & $\begin{array}{l}\text { Accession } \\
\text { No. }\end{array}$ & $\begin{array}{l}\% \text { Growth } \\
\text { inhibition of } \\
\text { P. aphanider- } \\
\text { matum }\end{array}$ & $\begin{array}{l}\text { \% Growth } \\
\text { Inhibition of } \\
\text { R. solani }\end{array}$ \\
\hline 1 & $\begin{array}{l}\text { Chamaraja nagar, Karnataka } \\
12.0526^{\circ} \mathrm{N}, 77.2865^{\circ} \mathrm{E}\end{array}$ & BSR 2 & RBacDOB-S1 & $\begin{array}{l}\text { Pseudomonas } \\
\text { plecoglossicida }\end{array}$ & 98 & KY818291 & $65.0 \pm 0.79^{\mathrm{h}}$ & $63.6 \pm 0.77^{\mathrm{i}}$ \\
\hline 2 & $\begin{array}{l}\text { Kollegal, Karnataka } \\
12.1537^{\circ} \mathrm{N}, 77.1111^{\circ} \mathrm{E}\end{array}$ & BSR 2 & RBacDOB-S4 & $\begin{array}{l}\text { Pseudomonas } \\
\text { plecoglossicida }\end{array}$ & 97 & KY818292 & $74.6 \pm 0.57^{\mathrm{b}}$ & $72.2 \pm 0.65^{\mathrm{c}}$ \\
\hline 3 & $\begin{array}{l}\text { Dharwad, Karnataka } \\
15.4589^{\circ} \mathrm{N}, 75.0078^{\circ} \mathrm{E}\end{array}$ & Local & RbacDOB-S6 & $\begin{array}{l}\text { Stenotrophomonas } \\
\text { sp. }\end{array}$ & 99 & KY883574 & $71.8 \pm 0.37^{\mathrm{d}}$ & $65.2 \pm 0.77^{\mathrm{h}}$ \\
\hline 4 & $\begin{array}{l}\text { Dharwad, Karnataka } \\
15.4589^{\circ} \mathrm{N}, 75.0078^{\circ} \mathrm{E}\end{array}$ & Local & RBacDOB-S9 & $\begin{array}{l}\text { Stenotrophomonas } \\
\text { maltophilia }\end{array}$ & 97 & KY883576 & $67.6 \pm 0.33^{\mathrm{f}}$ & $67.9 \pm 0.57^{\mathrm{f}}$ \\
\hline 5 & $\begin{array}{l}\text { Dakshina Kannada, Karnataka } \\
12.8438^{\circ} \mathrm{N}, 75.2479^{\circ} \mathrm{E}\end{array}$ & Local & RbacDOB-S10 & $\begin{array}{l}\text { Pseudomonas } \\
\text { monteilii }\end{array}$ & 99 & KY883577 & $67.3 \pm 0.5^{\mathrm{f}}$ & $67.5 \pm 0.33^{\mathrm{f}}$ \\
\hline 6 & $\begin{array}{c}\text { Dakshina Kannada, Karnataka } \\
12.8438^{\circ} \mathrm{N}, 75.2479^{\circ} \mathrm{E}\end{array}$ & Local & RbacDOB-S11 & $\begin{array}{l}\text { Pseudomonas } \\
\text { aeruginosa }\end{array}$ & 97 & KY883578 & $58.9 \pm 0.79^{1}$ & $64.2 \pm 0.75^{\mathrm{h}}$ \\
\hline 7 & $\begin{array}{l}\text { Erode, Tamilnadu } \\
11.3410^{\circ} \mathrm{N}, 77.7172^{\circ} \mathrm{E}\end{array}$ & Erode Local & RBacDOB-S14 & $\begin{array}{l}\text { Pseudomonas } \\
\text { aeruginosa }\end{array}$ & 99 & KY883580 & $56.2 \pm 0.56^{\mathrm{n}}$ & $53.6 \pm 0.33^{\circ}$ \\
\hline 8 & $\begin{array}{c}\text { Chamarajanagar, Karnataka } \\
12.0526^{\circ} \mathrm{N}, 77.2865^{\circ} \mathrm{E}\end{array}$ & BSR 1 & RbacDOB-S16 & $\begin{array}{l}\text { Stenotrophomonas } \\
\text { maltophilia }\end{array}$ & 98 & KY883582 & $73.7 \pm 0.73^{\mathrm{c}}$ & $71.4 \pm 0.37^{\mathrm{d}}$ \\
\hline 9 & $\begin{array}{c}\text { Chamarajanagar, Karnataka } \\
12.0526^{\circ} \mathrm{N}, 77.2865^{\circ} \mathrm{E}\end{array}$ & BSR 1 & RBacDOB-18 & Brevibacillus agri & 98 & KY883583 & $57.0 \pm 0.32^{\mathrm{m}}$ & $59.0 \pm 0.54^{1}$ \\
\hline 10 & $\begin{array}{l}\text { Hassan, Karnataka } \\
13.0068^{\circ} \mathrm{N}, 76.0996^{\circ} \mathrm{E}\end{array}$ & Local & RbacDOB-S20 & $\begin{array}{l}\text { Pseudomonas } \\
\text { hibiscicola }\end{array}$ & 97 & KY883584 & $73.2 \pm 0.57^{\mathrm{c}}$ & $57.6 \pm 0.73^{\mathrm{m}}$ \\
\hline 11 & $\begin{array}{c}\text { Bavanisagar, Tamilnadu } \\
11.4792^{\circ} \mathrm{N}, 77.1341^{\circ} \mathrm{E}\end{array}$ & BSR 2 & RbacDOB-S21 & $\begin{array}{l}\text { Pseudomonas } \\
\text { putida }\end{array}$ & 98 & KY883585 & $79.8 \pm 0.97^{\mathrm{a}}$ & $74.6 \pm 0.59^{\mathrm{b}}$ \\
\hline 12 & $\begin{array}{l}\text { Dharwad, Karnataka } \\
15.4589^{\circ} \mathrm{N}, 75.0078^{\circ} \mathrm{E}\end{array}$ & Local & RbacDOB-S23 & $\begin{array}{l}\text { Pseudomonas } \\
\text { aeruginosa }\end{array}$ & 98 & KY883586 & $59.3 \pm 0.57^{1}$ & $65.0 \pm 0.67^{\mathrm{h}}$ \\
\hline 13 & $\begin{array}{l}\text { Gobi, Tamilnadu } \\
11.4504^{\circ} \mathrm{N}, 77.4300^{\circ} \mathrm{E}\end{array}$ & BSR 2 & RbacDOB-S24 & Bacillus cereus & 99 & KY883587 & $79.8 \pm 0.37^{\mathrm{a}}$ & $76.6 \pm 0.87^{\mathrm{a}}$ \\
\hline 14 & $\begin{array}{l}\text { Coimbatore, Tamilnadu } \\
11.0168^{\circ} \mathrm{N}, 76.9558^{\circ} \mathrm{E}\end{array}$ & BSR 2 & RBacDOB-S26 & $\begin{array}{l}\text { Bacillus } \\
\text { thuringiensis }\end{array}$ & 99 & KY883598 & $66.0 \pm 0.33^{\mathrm{g}}$ & $66.2 \pm 0.33^{\mathrm{g}}$ \\
\hline 15 & $\begin{array}{l}\text { Coimbatore, Tamilnadu } \\
11.0168^{\circ} \mathrm{N}, 76.9558^{\circ} \mathrm{E}\end{array}$ & BSR 2 & RbacDOB-S29 & $\begin{array}{l}\text { Pseudomonas } \\
\text { alcaliphila }\end{array}$ & 98 & KY883588 & $65.0 \pm 0.67^{\mathrm{h}}$ & $69.5 \pm 0.57^{\mathrm{e}}$ \\
\hline 16 & $\begin{array}{l}\text { Dharwad, Karnataka } \\
15.4589^{\circ} \mathrm{N}, 75.0078^{\circ} \mathrm{E}\end{array}$ & Local & RbacDOB-S30 & $\begin{array}{l}\text { Pseudomonas } \\
\text { putida }\end{array}$ & 97 & KY883589 & $60.2 \pm 0.77^{\mathrm{k}}$ & $60.0 \pm 0.81^{\mathrm{k}}$ \\
\hline 17 & $\begin{array}{l}\text { Kollegal, Karnataka } \\
12.1537^{\circ} \mathrm{N}, 77.1111^{\circ} \mathrm{E}\end{array}$ & Salem local & RbacDOB-S35 & $\begin{array}{l}\text { Bacillus } \\
\text { megaterium }\end{array}$ & 99 & KY883590 & $57.4 \pm 0.61^{\mathrm{m}}$ & $59.0 \pm 0.57^{1}$ \\
\hline 18 & $\begin{array}{l}\text { Calicut, Kerala } \\
11.2588^{\circ} \mathrm{N}, 75.7804^{\circ} \mathrm{E}\end{array}$ & $\begin{array}{l}\text { Alleppey } \\
\text { Finger }\end{array}$ & RbacDOB-S36 & $\begin{array}{l}\text { Stenotrophomonas } \\
\text { maltophilia }\end{array}$ & 97 & KY883591 & $61.1 \pm 0.57^{\mathrm{j}}$ & $61.4 \pm 0.44^{\mathrm{j}}$ \\
\hline 19 & $\begin{array}{l}\text { Calicut, Kerala } \\
11.2588^{\circ} \mathrm{N}, 75.7804^{\circ} \mathrm{E}\end{array}$ & $\begin{array}{l}\text { Alleppey } \\
\text { Finger }\end{array}$ & RbacDOB-S40 & $\begin{array}{l}\text { Stenotrophomonas } \\
\text { maltophilia }\end{array}$ & 97 & KY883592 & $58.8 \pm 0.77^{1}$ & $61.0 \pm 0.57^{\mathrm{j}}$ \\
\hline 20 & $\begin{array}{l}\text { Salem, Tamilnadu } \\
11.6643^{\circ} \mathrm{N}, 78.1460^{\circ} \mathrm{E}\end{array}$ & Salem local & RbacDOB-S41 & $\begin{array}{l}\text { Pseudomonas } \\
\text { plecoglossicida }\end{array}$ & 98 & KY883593 & $61.8 \pm 0.59^{j}$ & $64.2 \pm 0.33^{\mathrm{h}}$ \\
\hline 21 & $\begin{array}{l}\text { Mysore, Karnataka } \\
12.2958^{\circ} \mathrm{N}, 76.6394^{\circ} \mathrm{E}\end{array}$ & Local & RbacDOB-S51 & $\begin{array}{l}\text { Pseudomonas } \\
\text { stutzeri }\end{array}$ & 98 & KY883594 & $63.4 \pm 0.75^{\mathrm{i}}$ & $60.0 \pm 0.57^{\mathrm{k}}$ \\
\hline 22 & $\begin{array}{l}\text { H.D.kote, Karnataka } \\
12.0879^{\circ} \mathrm{N}, 76.331^{\circ} \mathrm{E}\end{array}$ & Local & RbacDOB-S52 & Ochrobactrum sp. & 98 & KY883595 & $56.0 \pm 0.67^{\mathrm{n}}$ & $58.2 \pm 0.37^{1}$ \\
\hline 23 & $\begin{array}{l}\text { Guntur, Andrapradesh } \\
16.3067^{\circ} \mathrm{N}, 80.4365^{\circ} \mathrm{E}\end{array}$ & Duggirala & RbacDOB-S53 & $\begin{array}{l}\text { Pseudomonas } \\
\text { aeruginosa }\end{array}$ & 97 & KY883596 & $66.7 \pm 0.66^{\mathrm{g}}$ & $68.9 \pm 0.97^{\mathrm{e}}$ \\
\hline 24 & $\begin{array}{l}\text { Hassan, Karnataka } \\
13.0068^{\circ} \mathrm{N}, 76.0996^{\circ} \mathrm{E}\end{array}$ & Local & RbacDOB-S56 & Bacillus cereus & 98 & KY883597 & $56.0 \pm 0.57^{\mathrm{n}}$ & $57.6 \pm 0.91^{\mathrm{m}}$ \\
\hline 25 & $\begin{array}{l}\text { H.D.Kote, Karnataka } \\
12.0879^{\circ} \mathrm{N}, 76.331^{\circ} \mathrm{E}\end{array}$ & Local & RBacDOB-S & $\begin{array}{l}\text { Exiquebacterium } \\
\text { aurantiacum }\end{array}$ & 99 & KY924598 & $50.1 \pm 0.77^{q}$ & $53.0 \pm 0.87^{\circ}$ \\
\hline
\end{tabular}


Table 1. Continued

\begin{tabular}{|c|c|c|c|c|c|c|c|}
\hline $\begin{array}{l}\text { Sl } \\
\text { No }\end{array}$ & Geographical location (GPS) & $\begin{array}{l}\text { Variety of } \\
\text { turmeric }\end{array}$ & $\begin{array}{c}\text { Rhizospheric } \\
\text { bacterial isolate } \\
\text { (PGPR) }\end{array}$ & $\begin{array}{c}\% \\
\text { Identity }\end{array}$ & $\begin{array}{l}\text { Accession } \\
\text { No. }\end{array}$ & $\begin{array}{c}\% \text { Growth } \\
\text { inhibition of } \\
\text { P. aphanider- } \\
\text { matum }\end{array}$ & $\begin{array}{c}\% \text { Growth } \\
\text { Inhibition of } \\
\text { R. solani }\end{array}$ \\
\hline 26 & $\begin{array}{l}\text { Wayanad, Kerala } \\
11.6854^{\circ} \mathrm{N}, 76.1320^{\circ} \mathrm{E}\end{array}$ & $\begin{array}{l}\text { Alleppey } \\
\text { Finger }\end{array}$ & RBacDOB-S62 Acinetobacter sp. & 97 & KY971450 & $50.1 \pm 0.57^{q}$ & $52.6 \pm 0.81^{\circ}$ \\
\hline 27 & $\begin{array}{l}\text { Kadapa, Andhra Pradesh } \\
14.4674^{\circ} \mathrm{N}, 78.8241^{\circ} \mathrm{E}\end{array}$ & Tekurpeta & RBac-DOBS70 Enterobacter sp. & 99 & KY971459 & $70.1 \pm 0.73^{\mathrm{e}}$ & $69.0 \pm 0.57^{\mathrm{e}}$ \\
\hline 28 & $\begin{array}{r}\text { Kadapa, Andhra Pradesh } \\
14.4674^{\circ} \mathrm{N}, 78.8241^{\circ} \mathrm{E}\end{array}$ & Sugandham & RbacDOB-S72 Rhizobium pusense & 98 & KY883605 & $63.1 \pm 0.57^{\mathrm{i}}$ & $61.8 \pm 0.53^{\mathrm{j}}$ \\
\hline 29 & $\begin{array}{l}\text { Calicut, Kerala } \\
11.2588^{\circ} \mathrm{N}, 75.7804^{\circ} \mathrm{E}\end{array}$ & $\begin{array}{l}\text { Alleppey } \\
\text { Finger }\end{array}$ & $\begin{array}{r}\text { RBacDOB-S74 Brevibacillus } \\
\text { brostelensis }\end{array}$ & 99 & KY982872 & $54.6 \pm 0.63^{\circ}$ & $54.6 \pm 0.97^{\mathrm{n}}$ \\
\hline 30 & $\begin{array}{l}\text { Salem, Tamilnadu } \\
11.6643^{\circ} \mathrm{N}, 78.1460^{\circ} \mathrm{E}\end{array}$ & Salem local & $\begin{array}{c}\text { RBacDOB-S78 Alcaligenes } \\
\text { faecalis }\end{array}$ & 99 & KY982875 & $53.0 \pm 0.97^{\mathrm{p}}$ & $57.0 \pm 0.85^{\mathrm{m}}$ \\
\hline
\end{tabular}

Values are the mean of three independent replicates $(n=3) . \pm$ indicate standard errors. Mean followed by the same letter (s) within the same column are not significantly $(P \leq 0.05)$ different according to Tukey's HSD.

prepared containing population densities of $3 \times 10^{8}$ bacteria/g talc powder (Shanmugam et al., 2011). The talc based formulations $20 \mathrm{~g} / \mathrm{L}$ of each rhizospheric bacteria $P$. putida RBacDOB-S21, B. cereus RBacDOB-S24 and endophytic bacterial isolates $P$. aeruginosa BacDOB-E19, Enterobacteria sp. BacDOB-E21 were applied as rhizome treatment. The rhizomes were surface sterilized with $2 \%$ sodium hypochlorite for $1 \mathrm{~min}$ and soaked in sterile distilled water containing $20 \mathrm{~g} / 1$ formulation. The suspension was drained off after $12 \mathrm{~h}$ and the rhizomes were air dried overnight under a sterile air stream. The rhizomes with three nodes were planted in earthen pots containing sterilized soil of $5 \mathrm{~kg}$.

For first set of experiment, the pathogen $P$. aphanidermatum was multiplied on sand-corn meal medium and the rhizomes were infected after 30 days of planting at a ratio of 1:19 (sand-maize inoculum: soil), i.e., $300 \mathrm{~g}$ having 16 $\times 10^{4} \mathrm{cfu} \mathrm{g}^{-1}$ of medium per pot (Shanmugam et al., 2013). For second set, the 30 day old BCA treated turmeric plants were challenge inoculated with $R$. solani by inserting young immature sclerotia, 2 sclerotia per sheath (Sriraj et al., 2014).

Soil applications $(8 \mathrm{~g})$ of biocontrol formulation containing $3 \times 10^{8}$ bacteria/g talc powder was applied three times upto 90 days at intervals of 15 days for first set of plants ( $P$. aphanidermatum inoculated). For the second set of plants (R. solani inoculated) soil application of bacteria was followed by foliar spray of rhizospheric and endophytic bacteria at $10^{8}$ spores $/ \mathrm{ml}$ suspended in water.

Carbendazim $(0.1 \%)+$ Mancozeb $(0.25 \%)$ combination was applied for rhizome treatment and soil drenching (20 $\mathrm{ml}$ ) and for $R$. solani inoculated plants the rhizome and soil treatment was followed by spray of Carbendazim ( $0.1 \%)$
+ Mancozeb $(0.25 \%)$ served as fungicide control. The rhizomes without treatment and pathogens treated alone served as controls. The control plants showed systemic infection in 4-6 weeks of inoculation at temperature of 20$30^{\circ} \mathrm{C}$. The disease severity on rhizome was assessed and the PDI was calculated as described below

$$
\text { PDI }=\frac{\text { Number of infected plants }}{\text { Total number of inoculated plants }} \times 100
$$

The intensity of leaf blight disease was recorded after seven days of inoculation, with 0-9 scale of the Standard Evaluation System of rice, IRRI (2002) and expressed as percent disease index (Sriraj et al., 2014).

PDI $=\frac{\text { Sum of individual ratings }}{\text { Total number of plants observed }} \times \frac{100}{\text { Maximum grade }}$

A separate set with four treatments along with untreated control and pathogenic control was maintained for rhizome colonization assay and growth promotion studies. The plant length and fresh rhizome yield of the plants were recorded at the time of harvest.

Rhizome colonization assay by Confocal Microscopy. BCA (PGPR B. cereus and P. aeruginosa) treated turmeric rhizomes (as explained earlier) of 60 days old, were removed intact from the soil. The rhizomes were thoroughly washed in running tap water followed by distilled water. The rhizomes were surface sterilized with $2 \%(\mathrm{w} / \mathrm{v})$ sodium hypochoride solution for $30 \mathrm{~s}$. Experiments were performed twice, and rhizomes from three plants were 
Table 2. Molecular identification of endophytic bacteria isolated from turmeric rhizome using 16S rDNA region and their antagonistic effect on the pathogenic fungus $P$. aphanidermatum and $R$. solani

\begin{tabular}{|c|c|c|c|c|c|c|c|c|}
\hline $\begin{array}{r}\text { Sl } \\
\text { No. }\end{array}$ & Geographical location (GPS) & $\begin{array}{l}\text { Variety } \\
\text { of } \\
\text { turmeric }\end{array}$ & $\begin{array}{c}\text { Endophytic } \\
\text { bacterial isolate }\end{array}$ & $\begin{array}{l}\text { Closest related } \\
\text { sps. }\end{array}$ & $\begin{array}{c}\% \\
\text { Identity }\end{array}$ & $\begin{array}{l}\text { Accession } \\
\text { No. }\end{array}$ & $\begin{array}{l}\% \text { Growth } \\
\text { inhibition of } \\
P . \text { aphanider } \\
\text { matum }\end{array}$ & $\begin{array}{l}\% \text { Growth } \\
\text { inhibition of } \\
\text { R. solani }\end{array}$ \\
\hline 1 & $\begin{array}{c}\text { Chamaraja nagar, Karnataka } \\
12.0526^{\circ} \mathrm{N}, 77.2865^{\circ} \mathrm{E}\end{array}$ & BSR 2 & BacDOB-E2 & Alcaligenes faecalis & 97 & KY883599 & $64.0 \pm 0.57^{\mathrm{g}}$ & $67^{\mathrm{i}}$ \\
\hline 2 & $\begin{array}{l}\text { Hassan, Karnataka } \\
13.0068^{\circ} \mathrm{N}, 76.0996^{\circ} \mathrm{E}\end{array}$ & Local & BacDOB-E3 & Pseudomonas sp. & 99 & KY883600 & $61.6 \pm 0.44^{\mathrm{h}}$ & $65.2 \pm 0.33^{\mathrm{h}}$ \\
\hline 3 & $\begin{array}{l}\text { Kollegal, Karnataka } \\
12.1537^{\circ} \mathrm{N}, 77.1111^{\circ} \mathrm{E}\end{array}$ & BSR 2 & BacDOB-E4 & $\begin{array}{l}\text { Pseudomonas } \\
\text { aeruginosa }\end{array}$ & 99 & KY883601 & $69.0 \pm 0.77^{\mathrm{e}}$ & $67.0 \pm 0.57^{\mathrm{g}}$ \\
\hline 4 & $\begin{array}{l}\text { Dharwad, Karnataka } \\
15.4589^{\circ} \mathrm{N}, 75.0078^{\circ} \mathrm{E}\end{array}$ & Local & BacDOB-E5 & Citrobacter sp. & 99 & KY883602 & $70.8 \pm 0.57^{\mathrm{d}}$ & $68.2 \pm 0.43^{\mathrm{f}}$ \\
\hline 5 & $\begin{array}{l}\text { H.D Kote Karnataka } \\
12.0879^{\circ} \mathrm{N}, 76.331^{\circ} \mathrm{E}\end{array}$ & Local & BacDOB-E7 & $\begin{array}{l}\text { Terribacillus } \\
\text { saccharophilus }\end{array}$ & 98 & KY883603 & $57.0 \pm 0.63^{\mathrm{k}}$ & $59.4 \pm 0.57^{1}$ \\
\hline 6 & $\begin{array}{l}\text { Mysore, Karnataka } \\
12.2958^{\circ} \mathrm{N}, 76.6394^{\circ} \mathrm{E}\end{array}$ & Local & BacDOB-E8 & $\begin{array}{l}\text { Pseudomonas } \\
\text { aeruginosa }\end{array}$ & 99 & KY883604 & $69.6 \pm 0.49^{\mathrm{e}}$ & $68.9 \pm 0.33^{\mathrm{f}}$ \\
\hline 7 & $\begin{array}{l}\text { Dandeli, Karnataka } \\
15.2497^{\circ} \mathrm{N}, 74.6174^{\circ} \mathrm{E}\end{array}$ & Local & BacDOB-E9 & $\begin{array}{l}\text { Pseudomonas } \\
\text { plecoglossicida }\end{array}$ & 97 & KY883606 & $66.3 \pm 0.57^{\mathrm{f}}$ & $69.5 \pm 0.37^{\mathrm{e}}$ \\
\hline 8 & $\begin{array}{l}\text { Karnataka } \\
{ }^{\circ} \mathrm{N}, 75.7382^{\circ} \mathrm{E}\end{array}$ & Local & BacDOB-E11 & $\begin{array}{l}\text { Pseudomonas } \\
\text { aeruginosa }\end{array}$ & 99 & KY883607 & $58.9 \pm 0.63^{\mathrm{i}}$ & $60.2 \pm 0.57^{\mathrm{k}}$ \\
\hline 9 & $\begin{array}{l}\text { Kollegal, Karnataka } \\
12.1537^{\circ} \mathrm{N}, 77.1111^{\circ} \mathrm{E}\end{array}$ & BSR 1 & BacDOB-E12 & Acinetobacter sp. & 98 & KY924605 & $73.2 \pm 0.73^{\mathrm{c}}$ & $71.6 \pm 0.33^{\mathrm{d}}$ \\
\hline 10 & $\begin{array}{l}\text { Coimbatore, Tamilnadu } \\
11.0168^{\circ} \mathrm{N}, 76.9558^{\circ} \mathrm{E}\end{array}$ & BSR 2 & BacDOB-E14 & Alcaligenes sp. & 99 & KY776473 & $66.8 \pm 0.51^{\mathrm{e}}$ & $65.8 \pm 0.57^{\mathrm{h}}$ \\
\hline 11 & $\begin{array}{l}\text { milnadu } \\
\mathrm{N}, 78.1460^{\circ} \mathrm{E}\end{array}$ & Salem local & BacDOB-E15 & $\begin{array}{l}\text { Pseudomonas } \\
\text { aeruginosa }\end{array}$ & 99 & KY883608 & $73.8 \pm 0.61^{\mathrm{c}}$ & $72.6 \pm 0.77^{\mathrm{c}}$ \\
\hline 12 & $\begin{array}{l}\text { nilnadu } \\
\mathrm{N}, 77.4300^{\circ} \mathrm{E}\end{array}$ & Erode local & BacDOB-E17 & $\begin{array}{l}\text { Pseudomonas } \\
\text { aeruginosa }\end{array}$ & 99 & KY924595 & $58.0 \pm 0.33^{\mathrm{j}}$ & $60.0 \pm 0.79^{\mathrm{k}}$ \\
\hline 13 & $\begin{array}{c}\text { Bavanisagar, Tamilnadu } \\
11.4792^{\circ} \mathrm{N}, 77.1341^{\circ} \mathrm{E}\end{array}$ & BSR 2 & BacDOB-E18 & Arthrobacter sp. & 97 & KY924596 & $73.2 \pm 0.43^{\mathrm{c}}$ & $66.6 \pm 0.74^{\mathrm{g}}$ \\
\hline 14 & $\begin{array}{l}\text { Erode, Tamilnadu } \\
11.3410^{\circ} \mathrm{N}, 77.7172^{\circ} \mathrm{E}\end{array}$ & BSR 1 & BacDOB-E19 & $\begin{array}{l}\text { Pseudomonas } \\
\text { aeruginosa }\end{array}$ & 99 & KY924597 & $76.9 \pm 0.57^{\mathrm{a}}$ & $74.6 \pm 0.53^{\mathrm{a}}$ \\
\hline 15 & $\begin{array}{l}\text { Sathyamangalam, Tamilnadu } \\
11.5048^{\circ} \mathrm{N}, 77.2384^{\circ} \mathrm{E}\end{array}$ & BSR 2 & BacDOB-E20 & Bacillus cereus & 99 & KY924599 & $59.3 \pm 0.63^{\mathrm{i}}$ & $63.0 \pm 0.57^{\mathrm{i}}$ \\
\hline 16 & $\begin{array}{l}\text { Guntur, Andrapradesh } \\
16.3067^{\circ} \mathrm{N}, 80.4365^{\circ} \mathrm{E}\end{array}$ & Duggirala & BacDOB-E21 & Enterobacter sp. & 98 & KY924600 & $75.7 \pm 0.57^{b}$ & $73.4 \pm 0.87^{b}$ \\
\hline 17 & $\begin{array}{l}\text { Kadapa, Andrapradesh } \\
14.4674^{\circ} \mathrm{N}, 78.8241^{\circ} \mathrm{E}\end{array}$ & Sugandham & BacDOB-E22 & Bacillus cereus & 98 & KY924601 & $66.0 \pm 0.83^{\mathrm{e}}$ & $68.2 \pm 0.47^{\mathrm{f}}$ \\
\hline 18 & $\begin{array}{l}\text { Wayanad, Kerala } \\
11.6854^{\circ} \mathrm{N}, 76.1320^{\circ} \mathrm{E}\end{array}$ & $\begin{array}{l}\text { Alleppey } \\
\text { Finger }\end{array}$ & BacDOB-E34 & Acinetobacter sp. & 97 & KY924606 & $57.0 \pm 0.47^{\mathrm{k}}$ & $54.5 \pm 0.53^{\mathrm{n}}$ \\
\hline 19 & $\begin{array}{l}\text { Wayanad, Kerala } \\
11.6854^{\circ} \mathrm{N}, 76.1320^{\circ} \mathrm{E}\end{array}$ & $\begin{array}{l}\text { Alleppey } \\
\text { Finger }\end{array}$ & BacDOB-E47 & Enterobacter sp. & 98 & KY924602 & $61.2 \pm 0.77^{\mathrm{h}}$ & $62.0 \pm 0.59^{\mathrm{j}}$ \\
\hline 20 & $\begin{array}{l}\text { Calicut, Kerala } \\
11.2588^{\circ} \mathrm{N}, 75.7804^{\circ} \mathrm{E}\end{array}$ & $\begin{array}{l}\text { Alleppey } \\
\text { Finger }\end{array}$ & BacDOB-E52 & Klebsiella sp. & 99 & KY986971 & $57.2 \pm 0.33^{\mathrm{k}}$ & $58.6 \pm 0.77^{\mathrm{m}}$ \\
\hline
\end{tabular}

Values are the mean of three independent replicates $(\mathrm{n}=3) . \pm$ indicate standard errors. Mean followed by the same letter $(\mathrm{s})$ within the same column are not significantly $(P \leq 0.05)$ different according to Tukey's HSD.

analyzed for each data. The rhizome material $(1 \mathrm{~cm})$ was transferred to trichloroacetic acid fixation solution $(0.15 \%$ (wt/vol) trichloroacetic acid in 4:1 (vol/vol) ethanol/chloroform). Sections from rhizome were hand cut about $1 \mathrm{~cm}$ from the surface and approximately $50 \mu \mathrm{m}$ thick segments were mounted on a microscope slide. Bacteria in rhizome segments were stained by $5 \mu \mathrm{l}$ of Ethidium bromide (EtBr $1.25 \mathrm{mg} \mathrm{ml}^{-1}$ ) (Someya, 1995). Subsequently, segments were incubated at room temperature for $10 \mathrm{~min}$. After incubation the segments were mounted on clean glass slides 
and examined immediately. Confocal fluorescence images were recorded on Advanced Spectral Confocal Microscope System-LSM 710 (Carl Zeiss, Jena, Germany). It was excited with a 514-nm laser line and detected at 552-693 nm, Channels EtBr and T-PMT were used (Hansen et al., 1997).

Statistical analysis. Statistical analyses were performed using Ans. SPSS, Version 17 (Chicago, IL, USA) and MSExel version 2007 (Microsoft, Washington, DC, USA). A completely randomized design was used for all the experiments, with 3 replications for each treatment. Differences between experimental outcomes were analysed using Tukey's HSD test and $P \leq 0.05$ was considered not significantly different.

\section{Results}

Morphological and Biochemical traits of rhizospheric and endophytic bacteria isolated from turmeric. A total of 30 PGPR isolates from Rhizosphere and 20 endophytic bacteria from different geographic regions of South India viz., Karnataka, Kerala, Tamilnadu and Andhra Pradesh states were obtained. The isolates belonged to Bacillus, Pseudomonas, Arthrobacter, Enterobacter, Alcaligenes, Acinetobacter, Ochrobactrum, Exiquebacterium, Rhizobium, Klebsiella, Citrobacter and Terribacillus species. All the isolates were motile rods. Out of 50 isolates, 43 were Gramnegative while 7 were Gram-positive. Besides, 12 for methyl red test, 42 for citrate utilization, 33 for oxidase, 4 for VP, 22 for succinic acid production, 1 for starch hydrolysis, 31

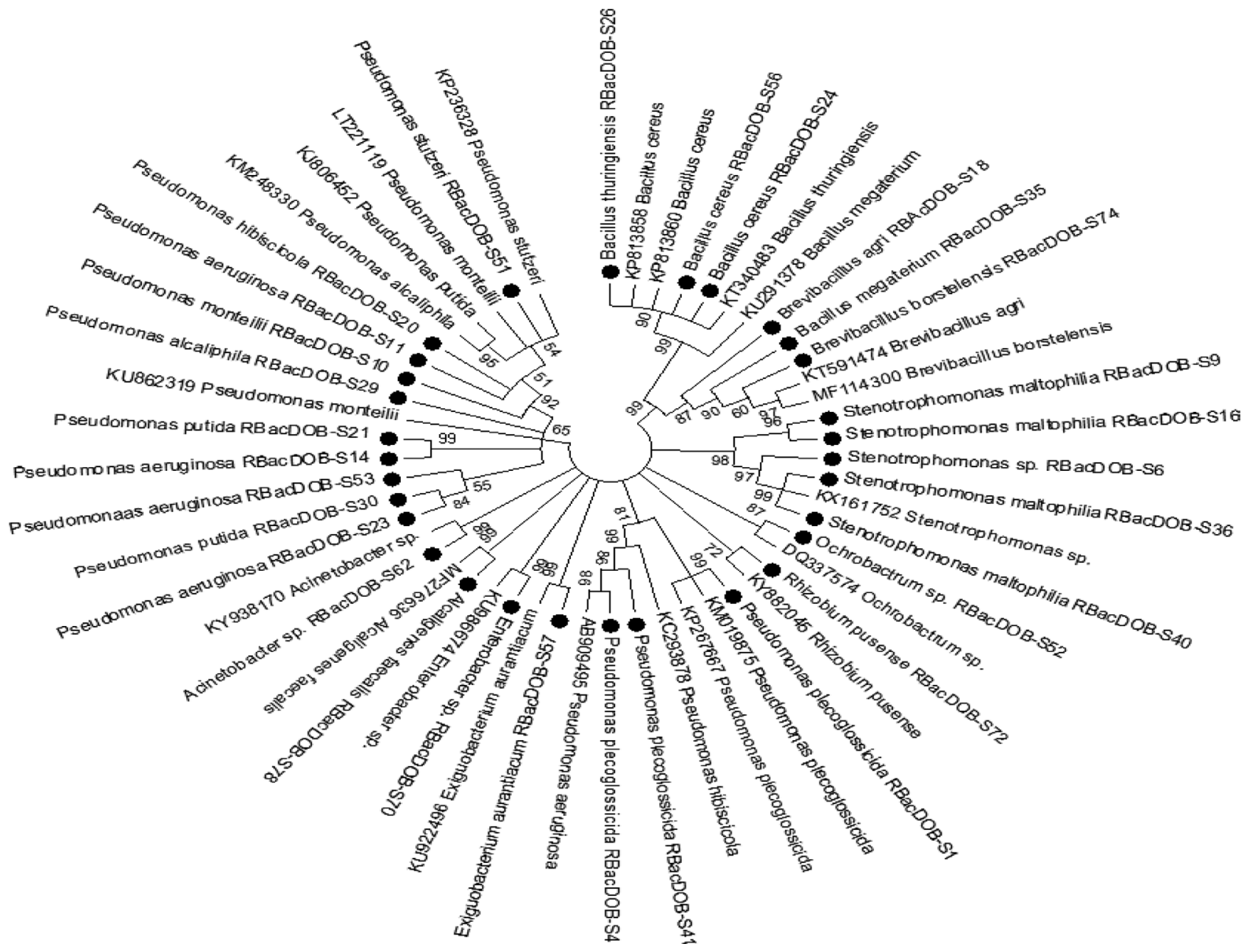

Fig. 1. Neighbor-joining tree based on analysis of partial $16 \mathrm{~s}$ rDNA nucleotide sequences of rhizospheric bacterial isolates of turmeric (•-symbol represents bacteria isolated in present study).The data of type strains of related species were from GenBank database. Numbers above and below the nodes indicate bootstrap values generated after 1000 replications. 
isolates for NH3 production, 41 isolates for casein hydrolysis were found positive, while all the isolates were positive for catalase production (Supplementary Table 1).

Molecular characterization of rhizospheric and endophytic bacteria. The quality of genomic DNA of rhizospheric and endophytic bacteria was good as evident from the ratio of 260/280, which was 1.72 . All the bacterial isolates the DNA was subjected to PCR amplification with specific primer for the 16s rDNA region which generated bands ranging from $630-700 \mathrm{bp}$. The sequences of $30 \mathrm{rhi}-$ zospheric and 20 endophytic bacterial isolates showed 97$99 \%$ similarity with the species in Genebank during Blast analysis. The Blast search confirmed the presence of Bacillus, Pseudomonas, Arthrobacter, Enterobacter, Alcaligenes, Acinetobacter, Ochrobactrum, Exiquebacterium, Rhizobium, Klebsiella, Citrobacter and Terribacillus species. All the 50 bacterial sequences were submitted to Genebank (NCBI) and their accession numbers were obtained (Table $1,2)$.

The Phylogenetic trees of rhizospheric and endophytic bacterial isolates constructed from 16s rDNA sequences along with the related reference species retrieved from Genbank of NCBI confirmed these isolates belong to $\mathrm{Ba}$ cillus, Pseudomonas, Arthrobacter, Enterobacter, Alcaligenes, Acinetobacter, Ochrobactrum, Exiquebacterium, Rhizobium, Klebsiella, Citrobacter and Terribacillus species by clustering of each of the isolate to its corresponding group (Fig. 1, 2).

In vitro antagonism. All the isolates were screened against $P$. aphanidermatum and $R$. solani by dual culture method (Fig. 1, 2). Five PGPR isolates viz., RBacDOBS4, RBacDOB-S16, RBacDOB-S21, RBacDOB-S24, $\mathrm{RBacDOB}-\mathrm{S} 70$ out of 30 rhizosoheric bacterial isolates and four endophytic bacteria BacDOB-E12, BacDOB-E15, BacDOB-E19, BacDOB-E21 out of 20 exhibited $>70 \%$ growth inhibition against both the pathogens (Table 1). SEM studies showed that the endophytes cause deformities in the mycelia of both $P$. aphanidermatum and $R$. solani pathogens. The deformities included hyphal fragmentation, perforation, desiccation of hyphae and mycelia degenera-

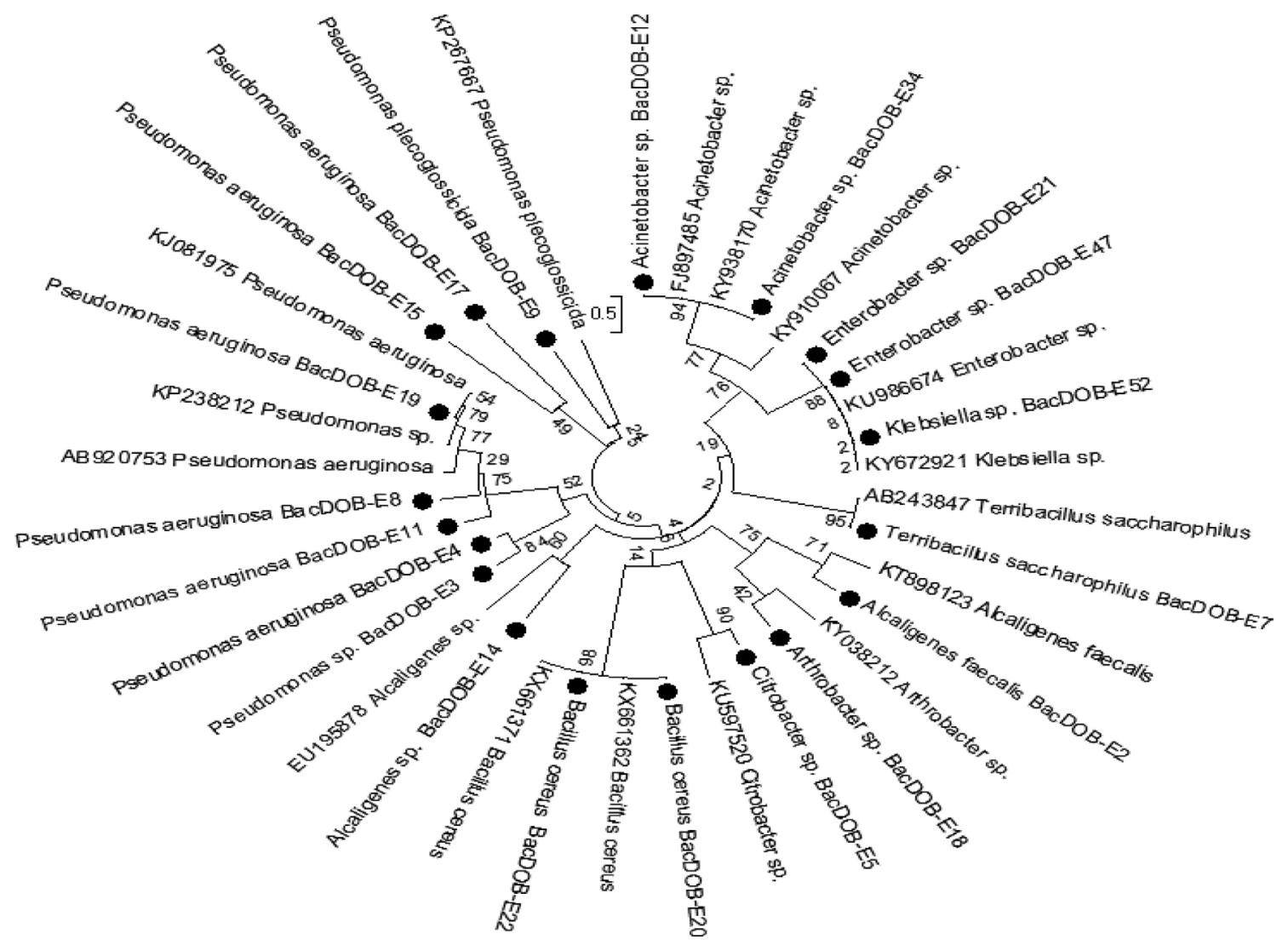

Fig. 2. Neighbor-joining tree based on analysis of partial 16s rDNA nucleotide sequences of endophytic isolates of turmeric (•- symbol represents bacteria isolated in present study). The data of type strains of related species were from GenBank database. Numbers above and below the nodes indicate bootstrap values generated after 1000 replications. 

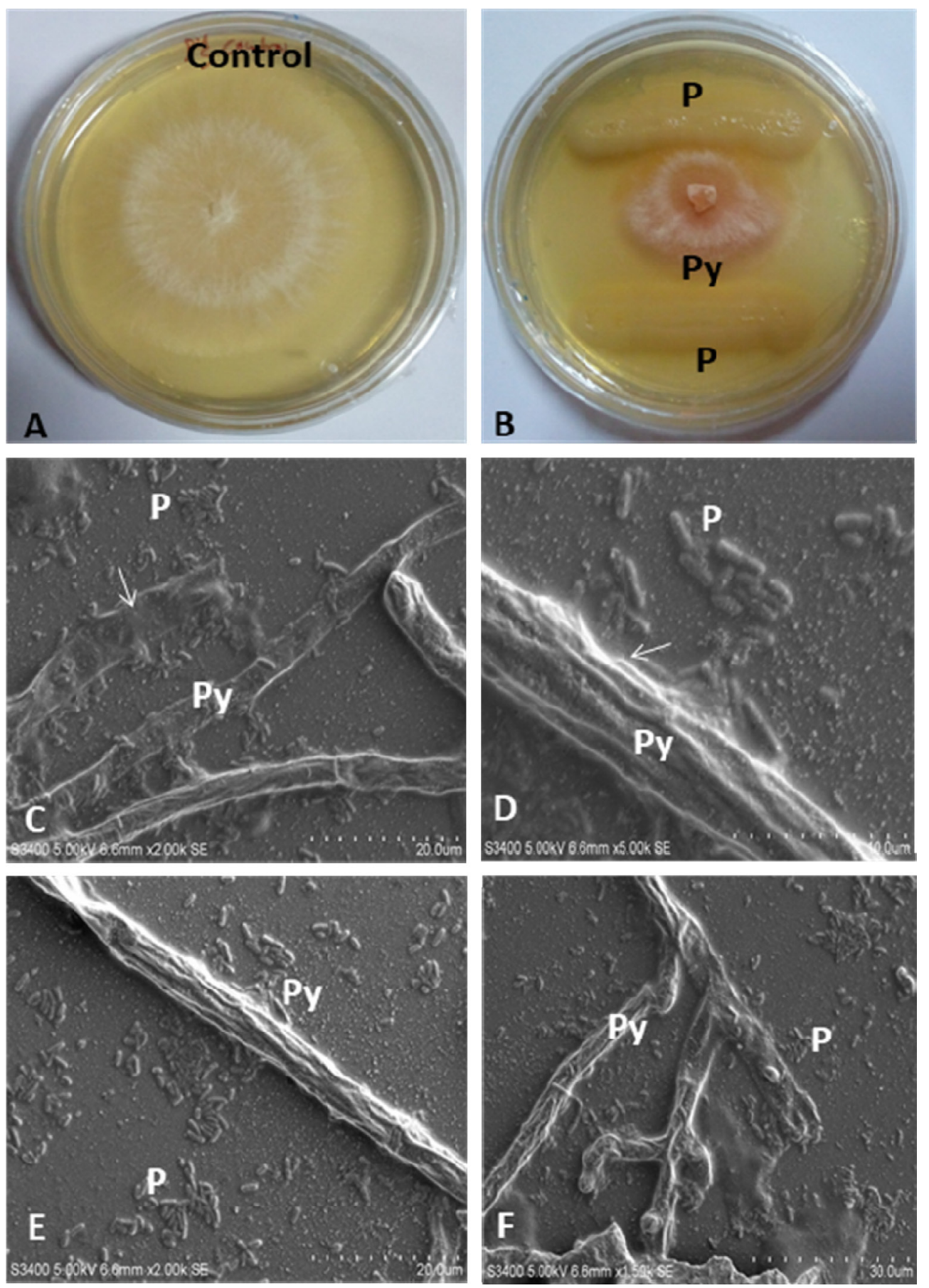

Fig. 3. Photographs of dual culture tests, A- P. aphanidermatum control, B-Dual culture of pathogen and endophytic bacterial isolate; Scanning electron micrograph showing morphological changes in $P$. aphanidermatum mycelia inhibited by endophytic bacterial isolate $P$. aeruginosa BacDOBE19; C- Breakage of hyphae, D and E- Lysis of hyphae, F-shows shrivelling and desication of the mycelium of $P$. aphanidermatum. $\mathrm{Py}=P$. aphanidermatum, $\mathrm{P}$ $=P$. aeruginosa.

tion (Fig. 3, 4) which finally resulted in fungal death.

In liquid dual culture assays $B$. cereus RBacDOB-S24 showed $86 \%$ and $84 \%$ growth inhibition of $P$. aphanidermatum and $R$. solani, followed by endophytic $P$. aeruginosa BacDOB- E19 that showed $85 \%$ and $82 \%$ growth inhibition respectively (Fig. 5, 6).

In vitro evaluation of plant growth promoting potentials. All the five rhizospheric PGPR isolates viz., RBac-
DOB-S4, RBacDOB-S16, RBacDOB-S21, RBacDOB$\mathrm{S} 24, \mathrm{RBacDOB}-\mathrm{S} 70$ and four endophytic bacterial isolates BacDOB-E12, BacDOB-E15, BacDOB-E19, BacDOBE21 were able to produce IAA with 1-tryptophan as a precursor. Except BacDOB-E12, the other isolates exhibited positive results for $\mathrm{HCN}$ production, while three isolates solubilized inorganic phosphate $\mathrm{Ca}_{3}\left(\mathrm{PO}_{4}\right)$ and four isolates were positive to cellulase activity. PGPR isolates RBacDOB-S21, RBacDOB-S24 and endophytic bacterial 

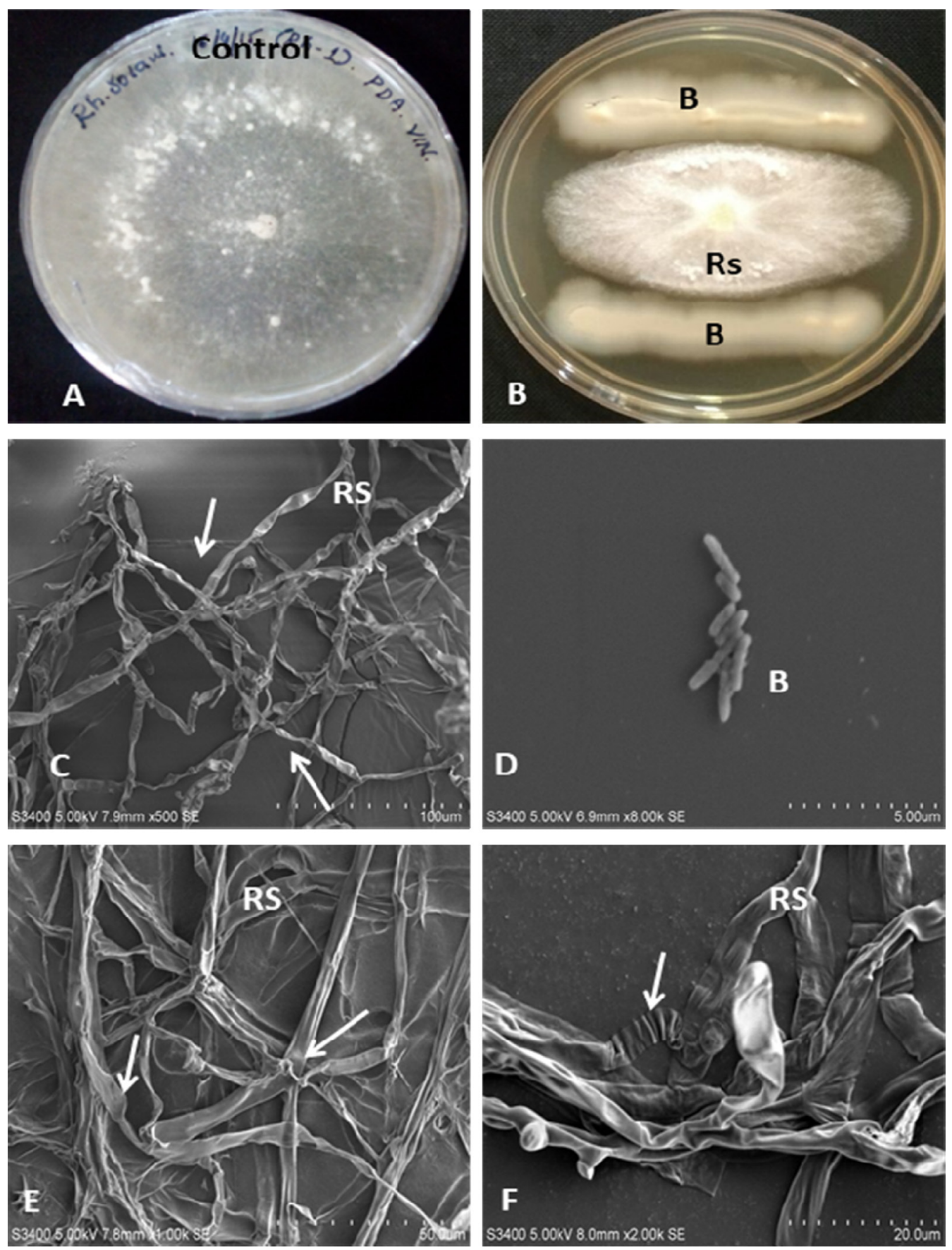

Fig. 4. Photographs of dual culture tests, A- R. solani control, B-Dual culture of pathogen and rhizospheric bacterial isolate RBacDOBS24 B. cereus; Scanning electron micrograph showing morphological changes in $R$. solani mycelia inhibited by rhizospheric bacterial isolate $B$. cereus RBacDOBS24; C- Breakage of hyphae, $\mathrm{E}$ and $\mathrm{F}$ - Arrow shows shrivelling and desication of the mycelium of $R$. solani. $\mathrm{RS}=$ $R$. solani, $\mathrm{B}=B$. Cereus.

isolates BacDOB-E19, BacDOB-E21 were positive for multiple PGP traits viz., IAA, HCN, Siderophore production, inorganic phosphate solubalization, production of cellulase and protease (Table 3, Supplementary Fig. 1).

Greenhouse experiments. The severity of leaf blight and rhizome rot disease was markedly reduced in the four individual treatments of rhizospheric PGPR isolates RBacDOB-S21, RBacDOB-S24; endophytic bacterial iso- lates BacDOB-E19 and BacDOB-E21. Isolate RBacDOBS24 significantly reduced the disease incidence of rhizome rot and leaf blight (by $16.4 \%$ and $15.5 \%$ respectively), followed by the endophytic bacterial isolate BacDOBE19 reduced the disease incidence of rhizome rot and leaf blight (by $17.5 \%$ to $17.7 \%$ ) respectively. The rhizospheric PGPR isolate RBacDOB-S24 enhanced the plant height to 89.09 and $86.71 \mathrm{~cm}$; fresh rhizome weight to 392 and 339 g against $P$. aphanidermatum and $R$. solani pathogens 


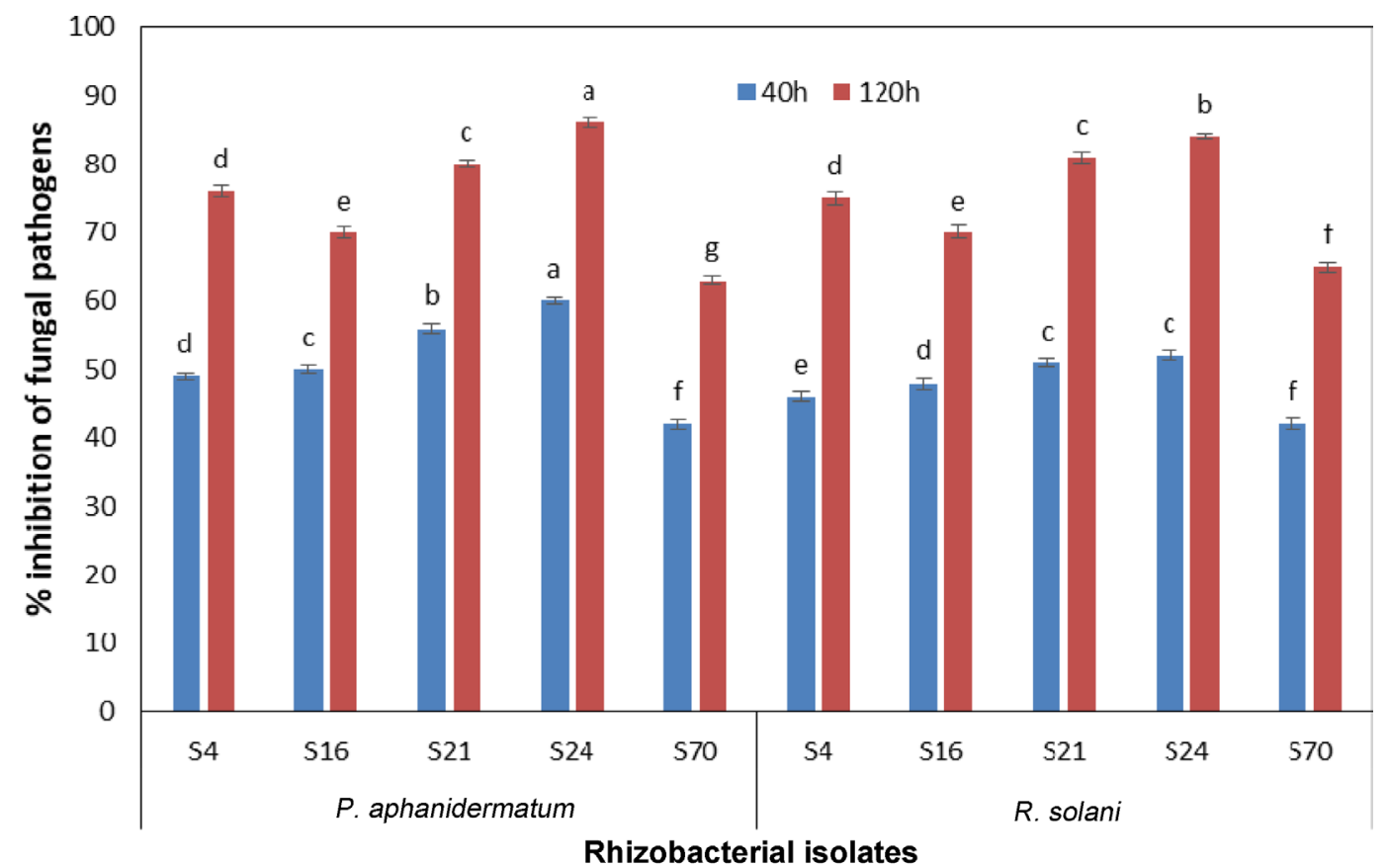

Fig. 5. Antagonistic activity of rhizospheric bacterial isolates against $P$. aphanidermatum and $R$. solani at two different time intervals in dual liquid culture assay.Py1 and Rh1 = $\%$ inhibition of fungi after $48 \mathrm{~h}$; Py 2 and $\mathrm{Rh} 2=\%$ inhibition of fungi after 120 $\mathrm{h}$. Each value is the mean for four replicates $(n=4)$ and bars sharing the same letters are not significantly different $(P \leq 0.05)$ according to Turkey's HSD. The vertical bars indicates the standard error.

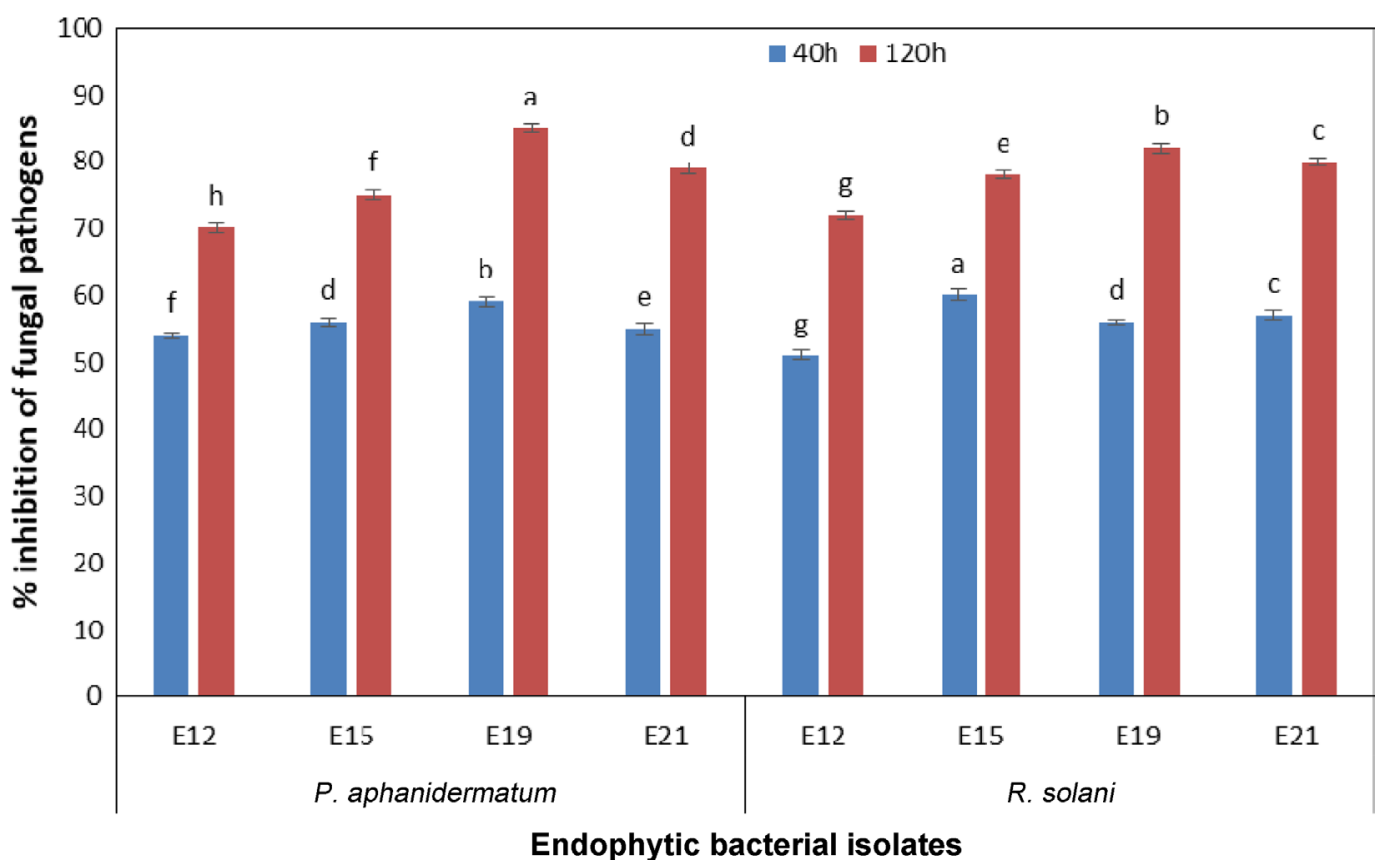

Fig. 6. Antagonistic activity of endophytic bacterial isolates against $P$. aphanidermatum and $R$. solani at two different time intervals in dual liquid culture assay. Pyl and Rh1 = $\%$ inhibition of fungi after 48 h; Py2 and Rh2 = \% inhibition of fungi after 120 $\mathrm{h}$. Each value is the mean for four replicates $(n=4)$ and bars sharing the same letters are not significantly different $(P \leq 0.05)$ according to Turkey's HSD. The vertical bars indicates the standard error.

respectively, followed by the endophytic isolate BacDOBE19 enhanced the plant height to 82.75 and $80.37 \mathrm{~cm}$; fresh rhizome weight 375 and 305 g respectively when compared to untreated control (Supplementary Table 2, Table 4, Fig. 7).

Rhizome colonization assay by Confocal Microscopy. The colonization in turmeric rhizomes was analysed by confocal microscopy. The results revealed that the PGPR $B$. cereus RBacDOB-S24 and endophyte $P$. aeruginosaBacDOB-E19 treated rhizomes showed colonization between the cells (Fig. 8).

\section{Discussion}

In this study, 30 PGPR were isolated from turmeric rhizosphere and 20 endophytes from healthy rhizome. The identity of the isolates was confirmed by morphological, 
Table 3. Characterization of selected rhizospheric and endophytic bacterial isolates for plant growth promoting potentials

\begin{tabular}{|c|c|c|c|c|c|c|c|c|}
\hline $\begin{array}{l}\text { Sl. } \\
\text { No. }\end{array}$ & Isolate No. & Species Identified & $\begin{array}{c}\text { IAA } \\
\text { production }\end{array}$ & $\begin{array}{c}\mathrm{HCN} \\
\text { production }\end{array}$ & $\begin{array}{c}\text { Phosphate } \\
\text { solubilization }\end{array}$ & $\begin{array}{c}\text { Cellulase } \\
\text { activity }\end{array}$ & $\begin{array}{c}\text { Protease } \\
\text { activity }\end{array}$ & $\begin{array}{l}\text { Siderophore } \\
\text { production }\end{array}$ \\
\hline \multicolumn{9}{|c|}{ Rhizospheric bacterial isolates } \\
\hline 1 & RBacDOB-S4 & Pseudomonas plecoglossicida & + & + & + & + & + & + \\
\hline 2 & RBacDOB-S16 & Stenotrophomonas maltophilia & + & + & + & + & + & + \\
\hline 3 & RBacDOB-S21 & Pseudomonas putida & + & + & + & + & + & + \\
\hline 4 & RBacDOB-S24 & Bacillus cereus & + & + & + & + & + & - \\
\hline 5 & RBacDOB-S70 & Enterobacter sp. & + & + & + & - & + & + \\
\hline \multicolumn{9}{|c|}{ Endophytic bacterial isolates } \\
\hline 1 & BacDOB-E12 & Acinetobacter sp. & + & + & + & - & + & + \\
\hline 2 & BacDOB-E15 & Pseudomonas aeruginosa & + & + & + & + & + & + \\
\hline 3 & BacDOB-E19 & Pseudomonas aeruginosa & + & + & + & + & + & + \\
\hline 4 & BacDOB-E21 & Enterobacter sp. & + & + & + & - & + & + \\
\hline
\end{tabular}

+ : represents positive, - : represents negative.

Table 4. Management of rhizome rot and leaf blight diseases of turmeric caused by $P$. aphanidermatum and $R$. solani by rhizospheric and endophytic bacterial isolates in green house

\begin{tabular}{|c|c|c|c|c|c|c|}
\hline \multirow[b]{2}{*}{ Treatment } & \multicolumn{3}{|c|}{ Rhizome rot } & \multicolumn{3}{|c|}{ Leaf blight } \\
\hline & $\begin{array}{c}\text { Fresh rhizome } \\
\text { weight }(\mathrm{g})\end{array}$ & $\begin{array}{l}\text { Plant length } \\
\text { (Cms) }\end{array}$ & PDI & $\begin{array}{l}\text { Fresh rhizome } \\
\text { weight }(\mathrm{g})\end{array}$ & $\begin{array}{l}\text { Plant length } \\
\text { (Cms) }\end{array}$ & PDI \\
\hline \multicolumn{7}{|l|}{ Rhizospheric bacterial isolates } \\
\hline B. cereus RBacDOB-S24 & $392 \pm 2.73^{\mathrm{a}}$ & $89.09 \pm 1.73^{\mathrm{a}}$ & $16.4 \pm 0.79^{\mathrm{f}}$ & $339 \pm 1.47^{\mathrm{a}}$ & $86.71 \pm 0.37^{\mathrm{a}}$ & $15.5 \pm 0.57^{\mathrm{f}}$ \\
\hline P. putida $\mathrm{RBacDOB}-\mathrm{S} 21$ & $381 \pm 2.51^{\mathrm{b}}$ & $83.17 \pm 1.37^{\mathrm{b}}$ & $18.2 \pm 0.47^{\mathrm{d}}$ & $327 \pm 1.74^{\mathrm{b}}$ & $82.57 \pm 0.75^{\mathrm{b}}$ & $16.6 \pm 0.73^{\mathrm{e}}$ \\
\hline \multicolumn{7}{|l|}{ Endophytic bacterial isolates } \\
\hline P. aeruginosa BacDOB-E19 & $375 \pm 1.79^{\mathrm{c}}$ & $82.75 \pm 1.27^{\mathrm{c}}$ & $17.5 \pm 0.73^{\mathrm{e}}$ & $305 \pm 1.72^{\mathrm{c}}$ & $80.37 \pm 0.77^{\mathrm{c}}$ & $17.7 \pm 0.32^{\mathrm{d}}$ \\
\hline Enterobacteria BacDOB-E21 & $362 \pm 2.23^{\mathrm{d}}$ & $81.65 \pm 1.57^{\mathrm{d}}$ & $20.7 \pm 0.43^{\mathrm{b}}$ & $290 \pm 1.23^{\mathrm{d}}$ & $78.60 \pm 1.31^{\mathrm{d}}$ & $18.8 \pm 1.07^{\mathrm{c}}$ \\
\hline Carbendazim $(0.1 \%)+$ Mancozeb $(0.25 \%)$ & $279 \pm 1.97^{\mathrm{e}}$ & $65.47 \pm 0.97^{\mathrm{e}}$ & $19.4 \pm 0.71^{\mathrm{c}}$ & $257 \pm 1.27^{\mathrm{e}}$ & $63.75 \pm 0.75^{\mathrm{e}}$ & $21.1 \pm 0.33^{\mathrm{b}}$ \\
\hline Uninoculated control & $257 \pm 1.79^{f}$ & $52.75 \pm 0.73^{\mathrm{f}}$ & 0.0 & $247 \pm 1.73^{\mathrm{f}}$ & $50.57 \pm 0.39^{f}$ & 0.0 \\
\hline Pathogenic control & $207 \pm 1.73^{\mathrm{g}}$ & $41.59 \pm 0.77^{\mathrm{g}}$ & $79.0 \pm 0.54^{\mathrm{a}}$ & $207 \pm 1.43^{\mathrm{g}}$ & $41.75 \pm 0.62^{\mathrm{g}}$ & $77.7 \pm 0.75^{\mathrm{a}}$ \\
\hline
\end{tabular}

The values are mean of three replications \pm SE. Mean followed by the same letter (s) within the same column are not significantly $(P \leq 0.05)$ different according to Tukey's HSD.

biochemical and 16S rDNA sequences. The 16S rDNA sequences were submitted to Genbank (NCBI) (Table 1). A majority of the isolates belonged to Bacillus, Pseudomonas, Arthrobacter, Enterobacter, Alcaligenes, Acinetobacter, Ochrobactrum, Exiquebacterium, Rhizobium, Klebsiella, Citrobacter and Terribacillus species. All the isolates (30 PGPR and 20 endophytes) were screened for nutrient solubilization, biochemical traits and antagonism in order to select the isolates that showed the most promising results with regard to growth promotion and biocontrol of rhizome rot and leaf blight diseases in turmeric plants.

Many of the soil-borne fungal diseases have been successfully controlled by the use of antagonists (Weller, 1988). The in vitro screening of rhizosphere bacterial isolates and endophytic bacteria for antagonism against $P$. aphanidermatum an $R$. solani indicated that nine isolates exhibited $>70 \%$ inhibition (Table 1,2 ) of both the pathogens in dual culture and liquid culture assays. Endophytic bacteria, used as whole cells (Rajendran and Samiyappan, 2008) and cell-free culture filtrates (Li et al., 2012) suppressed some plant pathogenic fungi due to antimicrobial compounds that cause alteration in structural architect and lysis of mycelia (Yuan et al., 2012). Our SEM results also revealed the morphological deformities of mycelia of both the pathogens. Similar observations have been reported in Pythium myriotylum due to the effect of extracellular metabolites by Bacillus sp. (Jimtha et al., 2016).

The rhizospheric and endophytic isolates have also exhibited significant plant growth promoting traits. Bacteria producing IAA promotes plant growth directly by increas- 

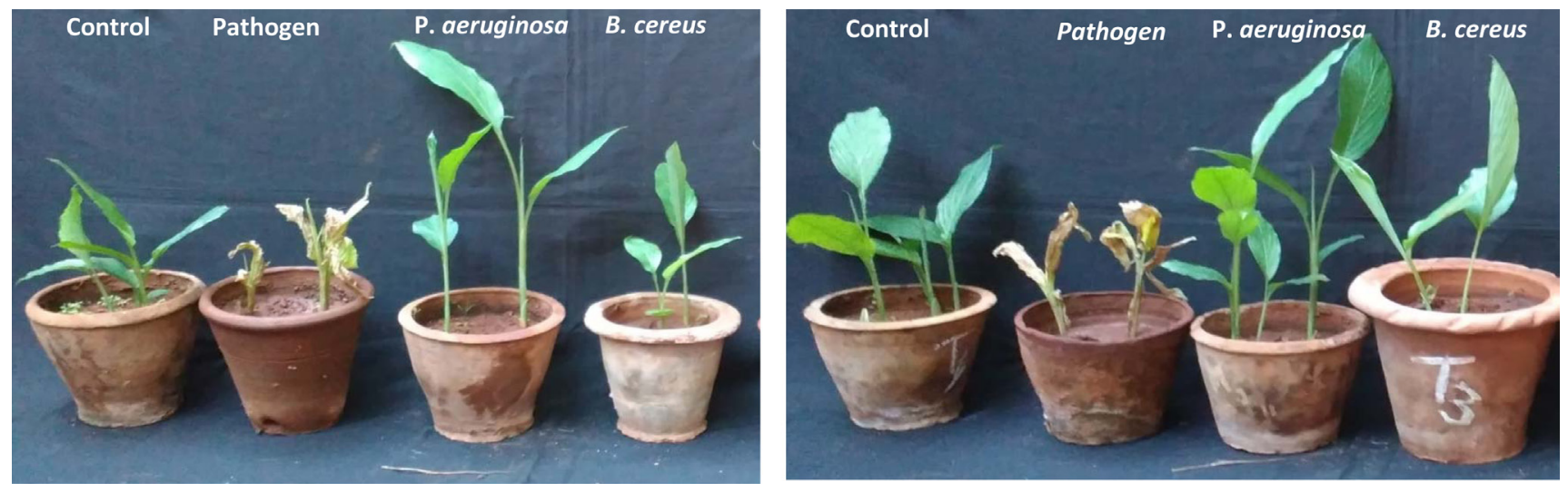

Fig. 7. Performance of antagonistic microbes against rhizome rot (P. aphanidermatum) and leaf blight ( $R$. solani) diseases in green house; A- Growth promotion of selected PGPR B. cereus RBacDOB-S24 and endophyte $P$. aeruginosa BacDOB-E19 antagonist, along with $P$. aphanidermatum pathogenic control and Untreated control. B- Growth promotion of selected PGPR B. cereus RBacDOB-S24 and endophyte $P$. aeruginosa BacDOB-E19 antagonist, along with $R$. solani pathogenic control and Untreated control.

ing root surface area and length by stimulating plant cell elongation or by affecting the cell division thereby providing greater access to soil nutrients by plants (Glick, 1995). In plant growth promotion analysis endophytic strains $P$. aeruginosa BacDOB-E19 and PGPR strains B. cereus RbacDOB-S24 produced significant amount of IAA, earlier reported in B. cereus (Rana et al., 2011) and P. putida (Jasim et al., 2014). Production of siderophores, indirectly influence the plant growth by binding to the available form of iron in the rhizosphere making it unavailable to the phytopathogens and protecting the plant health. Siderophore production by Bacillus sp. and Pseudomonas sp. in this study evidenced for one of the biocontrol mechanism similar to previous reports (Jasim et al., 2014; Kumar et al., 2016). Siderophore produced by Pseudomonas sp. has been reported to be an important mechanism of biological control of Pythium diseases (Matthijs et al., 2007). The results supported that endophytic and PGPR bacterial strains viz., B. cereus, $P$. aeruginosa, $P$. putida solubilize phosphate as reported previously for Bacillus sp. and $P$. putida (Forchetti et al., 2007; Pandey et al., 2006). In the present study, B. cereus and $P$. aeruginosa strains showed production of HCN similar to the previous results reported for Pseudomonas strains that controlled the plant root pathogens including $F$. oxysporum and $R$. solani by production of siderophores, HCN and lytic enzymes (Nagrajkumar et al., 2004). The selected strains $B$. cereus and $P$. aeruginosa produced cell wall degrading enzymes such as cellulases and proteases, which reported earlier as important in breakdown of cell walls of oomycete pathogens such as Phytopthora (Valois et al., 1996) and Pythium spp. (El-Tarabily et al., 2009). Similarly, the lytic enzyme production by rhizospheric $P$. fluorescence are known to be involved in the control of pathogens like $F$. oxysporum and $R$. solani (Nagrajkumar et al., 2004).

The four promising biocontrol agents (BCA's), two from rhizosphere and two from endophytes were then tested in the green house for their disease suppression and plant growth promotion abilities compared to untreated and pathogenic controls. Green house results suggested that the PGPR PGPR B. cereus and endophyte P. aeruginosa showed significant disease reduction also enhanced the yield of turmeric when compared to untreated control. Similar to our reports on turmeric, there are several studies on growth promotion by PGPR in other crops like maize (Egamberdiyeva, 2007), tomato (Almaghrabi et al., 2013), common bean (Martins et al., 2013) and ginger (Dinesh et al., 2015) have been reported. Endophyte B. cereus and $P$. fluorescens possesses biocontrol potential in crops like cotton and chilli, against root rot and damping off caused by $R$. solani and $P$. aphanidermatum respectively (Muthukumar et al., 2011; Pleban et al., 1997). Bacterial endophytes viz., $B$. cereus, $B$. thuringiensis, $B$. pumilis, $P$. putida and Clavibacter michiganensis, isolated from turmeric rhizomes exhibited PGP traits and antifungal activity against $F$. solani, A. pullulans, Alternaria alternata and $B$. fulva pathogens (Kumar et al., 2016). The culture supernatant of B. cereus QQ308 was active against numerous plant pathogenic fungi and has used in biological control (Chang et al., 2007). The potential of Bacillus cereus as a biocontrol agent against Fusarium solani causing rhizome rot in turmeric has been reported previously (Chauhan et al., 2016). Control of anthracnose rot caused by Colletotrichum acutatum in harvested loquat fruit inducing disease 

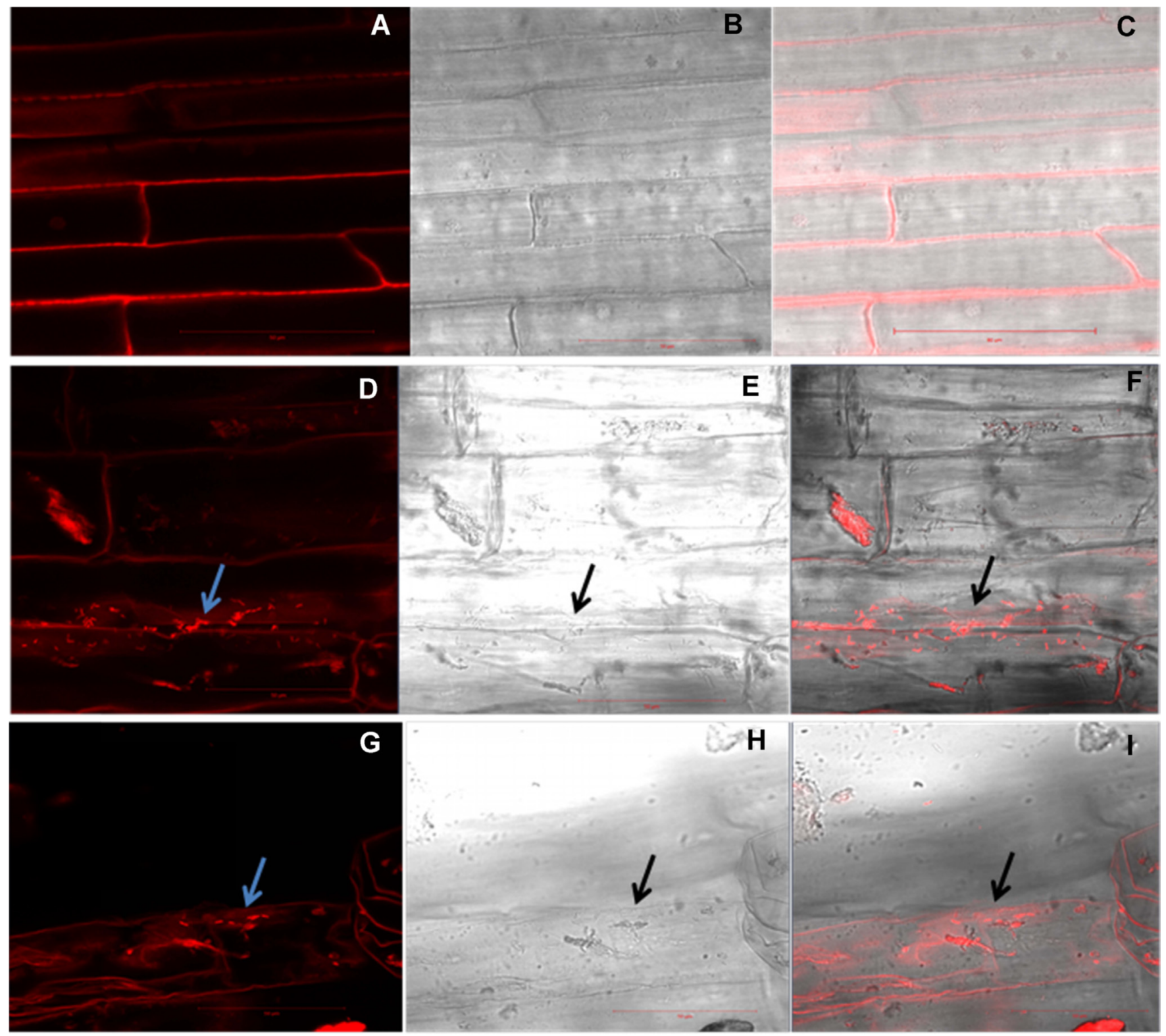

Fig. 8. Confocal microscopy observations of PGPR B. cereus RBacDOB-S24 and endophyte P. aeruginosa BacDOB-E19 treated 60 day old turmeric rhizome segments for colonization. (A-C) Control (untreated turmeric rhizomes), (D-F) PGPR B. cereus RBacDOBS24 treated rhizomes showing colonization between the cells (arrowheads), [(F) the overlay of fluroscence image (D) and T PMT field image (E)]. (G-I) Endophyte P. aeruginosa BacDOB-E19 treated rhizomes showing colonization between the cells (arrowheads) [(I) the overlay of fluroscence image $(\mathrm{G})$ and T PMT field image $(\mathrm{H})]$ (scale bars: $50 \mu \mathrm{m})$.

by biocontrol agent $B$. cereus was reported (Wang et al., 2014). The endophytes viz., $P$. aeruginosa, $P$. putida and $B$. megaterium associated with black pepper were reported as effective antagonists for biological control of Phytophthora foot rot which recorded over $70 \%$ disease suppression in green house trials (Aravind et al., 2009).

The PGPR isolated from rhizosphere of ginger viz., $B$. amyloliquefaciens and $S$. marcescens markedly reduced the soft rot incidence of ginger rhizome caused by $P$. myriotylum and showed marked increase in rhizome yield compared to chemical treatments (Dinesh et al., 2015). The potent PGPR strains should fulfill at least two of the criteria such as colonization, plant growth stimulation and biocontrol (Beneduzi et al., 2012). Nevertheless, in present study PGPR $B$. cereus and endophyte $P$. aeruginosa both possess direct PGP activities like IAA production and phosphate solubilization and indirect PGP activities like antifungal activity, siderophore, HCN production and produce lytic 
enzymes protease and cellulase. In vivo evidence suggest that PGPR B. cereus RBacDOB-S24 and endophyte $P$. aeruginosa BacDOB-E19 suppressed the disease incidence of rhizome rot and leaf blight significantly and expressed high yield. Hence, these strains can be explored as potential biocontrol agents in order to control the rhizome rot and leaf blight diseases in turmeric which helps to reform the chemical fungicide based disease management approaches.

The present study revealed the importance of isolating, screening of bacteria for multiple PGP and biocontrol traits through greenhouse experiments in turmeric. In this study, based on in vitro experiments, two strains viz., PGPR $B$. cereus $\mathrm{RBacDOB}-\mathrm{S} 24$ and endophyte $P$. aeruginosa BacDOB-E19 (Out of the 30 PGPR and 20 endophytes from turmeric) exhibited multiple plant growth promoting traits. The results of green house evidenced these strains suppressed the disease incidence of rhizome rot and leaf blight significantly, and markedly enhanced the yield in turmeric compared to untreated control and chemical treatments like Carbendazim- mancozeb. Also, B. cereus RBacDOBS24 and endophyte $P$. aeruginosa BacDOB-E19 treated rhizomes showed colonization in the cells. The study confirms the potential of PGPR B. cereus RBacDOB-S24 and endophyte $P$. aeruginosa BacDOB-E19 as biocontrol agents (BCA's) for sustainable turmeric cultivation. For the best of our knowledge, this is the first report on the strains PGPR B. cereus RBacDOB-S24 and endophyte $P$. aeruginosa BacDOB-E19 as biocontrol agents (BCA's) against $P$. aphanidermatum and $R$. solani pathogens of turmeric. Further studies concerning field applications and stable bioformulations are in progress.

\section{Conflicts of Interest}

The authors declare that they have no conflict of interests regarding the publication of this paper.

\section{Acknowledgments}

This work was carried out with the financial assistance from the Department of Science and Technology (DST), Government of India, New Dehli, under the Women Scientist Scheme (DST-WOS A) awarded to Mrs. Vinaya Rani. G (DST sanction No.SR/WOS-A/LS-104/2013 (G) dated 22.04.2014. The authors extend thanks to Dr. K. Ramachandra Kini, Associate Professor, Department of Biotechnology, University of Mysore, Mysore for his help in Phylogenetic analysis of endophytes. We also thank Institution of Excellence (IOE) at University of Mysore for providing instrumentation facility.

\section{References}

Ahmad, F., Ahmad, I. and Khan, M. S. 2008. Screening of freeliving rhizospheric bacteria for their multiple plant growth promoting activities. Microbiol. Res. 163:173-181.

Almaghrabi, O. A., Massoud, S. I. and Abdelmoneim, T. S. 2013. Influence of inoculation with plant growth promoting rhizobacteria (PGPR) on tomato plant growth and nematode reproduction under greenhouse conditions. Saudi J. Biol. Sci. 20:57-61.

Aravind, R., Kumar, A., Eapen, S. J. and Ramana, K. V. 2009. Endophytic bacterial flora in root and stem tissues of black pepper (Piper nigrum L.) genotype: isolation, identification and evaluation against Phytophthora capsici. Lett. Appl. Microbiol. 48:58-64.

Bashan, Y. and De-Bashan, L. E. 2005. Plant growth-promoting. In: Encyclopedia of soils in the environment. Vol. 1, pp. 103115.

Beneduzi, A., Ambrosini, A. and Passaglia, L. M. 2012. Plant growth-promoting rhizobacteria (PGPR): their potential as antagonists and bio control agents. Genet. Mol. Biol. 35:10441051.

Berg, G. and Hallmann, J. 2006. Control of plant pathogenic fungi with bacterial endophytes. In: Microbial root endophytes, pp. 53-69. Springer Berlin Heidelberg.

Berg, G., Krechel, A., Ditz, M., Faupel, A., Sikora, R. A., Ulrich, A. and Hallmann, J. 2005. Endophytic and ectophytic potatoassociated bacterial communities differ in structure and antagonistic function against plant pathogenic fungi. FEMS Microbiol. Ecol. 51:215-229.

Broekaert, W. F., Terras, F. R., Cammue, B. P. and Vanderleyden, J. 1990. An automated quantitative assay for fungal growth inhibition. FEMS Microbiol. Lett. 69:55-59.

Cao, L., Qiu, Z., You, J., Tan, H. and Zhou, S. 2005. Isolation and characterization of endophytic streptomycete antagonists of Fusarium wilt pathogen from surface-sterilized banana roots. FEMS Microbiol. Lett. 247:147-152.

Cappuccino, J. C. and Sherman, N. 1992. Microbiology: a Laboratory Manual. 3rd ed. pp. 125-179. Benjamin/Cummings Pub. Co., NY, USA.

Chang, W. T., Chen, Y. C. and Jao, C. L. 2007. Antifungal activity and enhancement of plant growth by Bacillus cereus grown on shellfish chitin wastes. Bioresour. Technol. 98:1224-1230.

Chauhan, A. K., Maheshwari, D. K., Kim, K. and Bajpai, V. K. 2016. Termitarium-inhabiting Bacillus endophyticus TSH42 and Bacillus cereus TSH77 colonizing Curcuma longa L.: isolation, characterization, and evaluation of their biocontrol and plant-growth-promoting activities. Can. J. Microbiol. 62:880-892.

Chernin, L. and Chet, I. 2002. Microbial enzymes in biocontrol of plant pathogens and pests. In: Enzymes in the environ- 
ment: activity, ecology, and applications, pp. 171-225. Marcel Dekker, NY, USA.

Compant, S., Duffy, B., Nowak, J., Clément, C. and Barka, E. A. 2005. Use of plant growth-promoting bacteria for biocontrol of plant diseases: principles, mechanisms of action, and future prospects. Appl. Environ. Microbiol. 71:4951-4959.

Dinesh, R., Anandaraj, M., Kumar, A., Bini, Y. K., Subila, K. P. and Aravind, R. 2015. Isolation, characterization, and evaluation of multi-trait plant growth promoting rhizobacteria for their growth promoting and disease suppressing effects on ginger. Microbiol. Res. 173:34-43.

Egamberdiyeva, D. 2007. The effect of plant growth promoting bacteria on growth and nutrient uptake of maize in two different soils. Appl. Soil Ecol. 36:184-189.

El-Tarabily, K. A., Nassar, A. H., Hardy, G. S. J. and Sivasithamparam, K. 2009. Plant growth promotion and biological control of Pythium aphanidermatum, a pathogen of cucumber, by endophytic actinomycetes. J. Appl. Microbiol. 106:13-26.

Forchetti, G., Masciarelli, O., Alemano, S., Alvarez, D. and Abdala, G. 2007. Endophytic bacteria in sunflower (Helianthus annuus L.): isolation, characterization, and production of jasmonates and abscisic acid in culture medium. Appl. Microbiol. Biotechnol. 76:1145-1152.

Glick, B. R. 1995. The enhancement of plant growth by free living bacteria. Can. J. Microbiol. 41:109-114.

Gordon, S. A. and Weber, R. P. 1951. Colorimetric estimation of indoleacetic acid. Plant Physiol. 26:192-195.

Hallmann, J., Davies, K. G. and Sikora, R. 2009. Biological control using microbial pathogens, endophytes and antagonists. In: Root-Knot Nematodes, pp. 380-411. CABI, Wallingford, UK.

Hansen, M., Kragelund, L., Nybroe, O. and Sorensen, J. 1997. Early colonization of barley roots by Pseudomonas fluorescens studied by immunofluorescence technique and confocal laser scanning microscopy. FEMS Microbiol. Ecol. 23:353360.

Holt, J. G., Krieg, N. R. and Sneath, P. H. A. 1994. Berger's manual of determinative bacteriology. 9th ed. Williams \& Wilkins, Baltimore, MD, USA.

IRRI. 2002. Standard Evaluation system for rice. International Rice Research Institute, Manila, Philippines. p.19.

Jasim, B., Joseph, A. A., John, C. J., Mathew, J. and Radhakrishnan, E. K. 2014. Isolation and characterization of plant growth promoting endophytic bacteria from the rhizome of Zingiber officinale. 3 Biotech 4:197-204.

Jimtha, J. C., Jishma, P., Arathy, G. B., Anisha, C. and Radhakrishnan, E. K. 2016. Identification of plant growth promoting Rhizosphere Bacillus sp. WG4 antagonistic to Pythium myriotylum and its enhanced antifungal effect in association with Trichoderma. J. Soil Sci. Plant Nutr. 16:578590.

Kavitha, K., Nakkeeran, S. and Chandrasekar, G. 2012. Rhizobacterial-mediated induction of defense enzymes to enhance the resistance of turmeric (Curcuma longa L) to Pythium aphanidermatum causing rhizome rot. Arch. Phytopathology Plant Protect. 45:199-219.

Kloeppe, J. W., Rodriguez-Kabana, R., Zehnder, A. W., Murphy, J. F., Sikora, E. and Fernandez, C. 1999. Plant root-bacterial interactions in biological control of soil borne diseases and potential extension to systemic and foliar diseases. Australas. Plant Pathol. 28:21-26.

Kloepper, J. W., Lifshitz, R. and Zablotowicz, R. M. 1989. Freeliving bacterial inocula for enhancing crop productivity. Trends Biotechnol. 7:39-44.

Kuffner, M., Puschenreiter, M., Wieshammer, G., Gorfer, M. and Sessitsch, A. 2008. Rhizosphere bacteria affect growth and metal uptake of heavy metal accumulating willows. Plant Soil 304:35-44.

Kumar, A., Singh, R., Yadav, A., Giri, D. D., Singh, P. K. and Pandey, K. D. 2016. Isolation and characterization of bacterial endophytes of Curcuma longa L. 3 Biotech 6:1-8.

Li, H., Wang, X., Han, M., Zhao, Z., Wang, M., Tang, Q., Liu, C., Kemp, B., Gu, Y., Shuang, J. and Xue, Y. 2012. Endophytic Bacillus subtilis ZZ120 and its potential application in control of replant diseases. Afr. J. Biotechnol. 11:231-242.

Lodewyckx, C., Vangronsveld, J., Porteous, F., Moore, E. R., Taghavi, S., Mezgeay, M. and der Lelie, D. V. 2002. Endophytic bacteria and their potential applications. CRC Crit. Rev. Plant Sci. 21:583-606.

Loper, J. E. and Schroth, M. N. 1986. Influence of bacterial sources of indole-3-acetic acid on root elongation of sugar beet. Phytopathology 76:386-389.

Lorck, H. 1948. Production of hydrocyanic acid by bacteria. Physiol. Plant. 1:142-146.

Martins, S. J., de Medeiros, F. H. V., de Souza, R. M., de Resende, M. L. V. and Ribeiro, P. M. 2013. Biological control of bacterial wilt of common bean by plant growth-promoting rhizobacteria. Biol. Control 66:65-71.

Matthijs, S., Tehrani, K. A., Laus, G., Jackson, R. W., Cooper, R. M. and Cornelis, P. 2007. Thioquinolobactin, a Pseudomonas siderophore with antifungal and anti-Pythium activity. Environ. Microbiol. 9:425-434.

Minaxi and Saxena, J. 2010. Characterization of Pseudomonas aeruginosa RM-3 as a potential biocontrol agent. Mycopathologia 170:181-193.

Muthukumar, A., Eswaran, A. and Sangeetha, G. 2011. Induction of systemic resistance by mixtures of fungal and endophytic bacterial isolates against Pythium aphanidermatum. Acta Physiol. Plant. 33:1933-1944.

Nagrajkumar, M., Bhaskaran, R. and Velazhahan, R. 2004. Involvement of secondary metabolites and extracellular lytic enzymes produced by Pseudomonas fluorescens in inhibition of Rhizoctonia solani, the rice sheath of blight pathogen. Microbiol. Res. 159:73-81.

Pandey, A., Trivedi, P., Kumar, B. and Palni, L. M. S. 2006. Characterization of a phosphate solubilizing and antagonistic strain of Pseudomonas putida (B0) isolated from a sub-alpine location in the Indian Central Himalaya. Curr. Microbiol. 
53:102-107.

Park, M. 1934. Report on the work of the mycology division. In: Administrative report of directorate of agriculture, pp. 126133. Ceylon.

Pikovskaya, R. I. 1948. Mobilization of phosphorus in soil in connection with vital activity of some microbial species. Mikrobiologiya 17:362-370.

Pillay, V. K. and Nowak, J. 1997. Inoculum density, temperature, and genotype effects on in vitro growth promotion and epiphytic and endophytic colonization of tomato (Lycopersicon esculentum L.) seedlings inoculated with a pseudomonad bacterium. Can. J. Microbiol. 43:354-361.

Pleban, S., Chernin, L. and Chet, I. 1997. Chitinolytic activity of an endophytic strain of Bacillus cereus. Lett. App. Microbiol. 25:284-288.

Rajendran, L. and Samiyappan, R. 2008. Endophytic Bacillus species confer increased resistance in cotton against damping off disease caused by Rhizoctonia solani. Plant Pathol. J. 7:112.

Ramarethinam, S. and Rajagopal, B. 1999. Efficacy of Trichoderma sp. organic amendments and seed dressing fungicides on rhizome rot of turmeric. Pestology 23:21-22.

Rana, A., Saharan, B., Joshi, M., Prasanna, R., Kumar, K. and Nain, L. 2011. Identification of multi-trait PGPR isolates and evaluating their potential as inoculants for wheat. Ann. Microbiol. 61:893-900.

Rathaiah, Y. 1982. Ridomil for control of rhizome rot of turmeric. Indian Phytopathol. 35:297-299.

Roy, A. K. 1992. Severity of Rhizoctonia solani on the leaves of rice and turmeric. Indian Phytopathol. 45:344-347.

Minaxi and Saxena, J. 2010. Characterization of Pseudomonas aeruginosa RM-3 as a potential biocontrol agent. Mycopathologia 170:181-193.

Schulz, B. J. E., Boyle, C. J. C. and Sieber, T. N. 2006. Microbial root endophytes, pp. 1-13. Springer-Verlag, Berlin.

Schwyn, B. and Neilands, J. B. 1987. Universal chemical assay for the detection and determination of siderophores. Anal. Biochem. 160:47-56.

Shanmugam, V., Gupta, A. K., Kanoujia, S. and Naruka, N. D. S. 2011. Selection and differentiation of Bacillus spp. Antagonistic to Fusarium oxysporum f.sp. lycopersici and Alternaria solani infecting tomato. Folia Microbiol. (Praha) 56:170177.

Shanmugam, V., Gupta, S. and Dohroo, N. P. 2013. Selection of a compatible biocontrol strain mixture based on co-cultivation to control rhizome rot of ginger. Crop Prot. 43:119-127.

Siddiqui, Z. A. 2005. PGPR: prospective biocontrol agents of plant pathogens. In PGPR: biocontrol and biofertilization, pp. 111-142. Springer, Netherlands.
Someya, T. 1995. Three-dimensional observation of soil bacteria in organic debris with a confocal laser scanning microscope. Soil Microorganisms 46:61-69.

Sriraj, P. P., Sundravadana, S. and Alice, D. 2014. Efficacy of fungicides, botanicals and bioagents against Rhizoctonia solani inciting leaf blight on turmeric (Curcuma longa L.). Afr. J. Microbiol. Res. 8:3284-3294.

Sturz, A. V., Christie, B. R. and Nowak, J. 2000. Bacterial endophytes: potential role in developing sustainable systems of crop production. CRC Crit. Rev. Plant Sci. 19:1-30.

Tamura, K., Peterson, D., Peterson, N., Stecher, G., Nei, M. and Kumar, S. 2011. MEGA5: molecular evolutionary genetics analysis using maximum likelihood, evolutionary distance, and maximum parsimony methods. Mol. Biol. Evol. 28:27312739 .

Thiripurasundari, K. and Selvarani, K. 2014. Production of turmeric in India: an analysis. Int. J. Bus. Manag. 2:229.

Thompson, J. D., Higgins, D. G. and Gibson, T. J. 1994. CLUSTAL W: improving the sensitivity of progressive multiple sequence alignment through sequence weighting, positionspecific gap penalties and weight matrix choice. Nucleic Acids Res. 22:4673-4680.

Valois, D., Fayad, K., Barasubiye, T., Garon, M., Dery, C., Brzezinski, R. and Beaulieu, C. 1996. Glucanolytic actinomycetes antagonistic to Phytophthora fragariae var. rubi, the causal agent of raspberry root rot. Appl. Environ. Microbiol. 62:1630-1635.

Verma, S. C., Ladha, J. K. and Tripathi, A. K. 2001. Evaluation of plant growth promoting and colonization ability of endophytic diazotrophs from deep water rice. J. Biotechnol. 91:127141.

Wakelin, S. A., Warren, R. A., Harvey, P. R. and Ryder, M. H. 2004. Phosphate solubilization by Penicillium spp. closely associated with wheat roots. Biol. Fert. Soils 40:36-43.

Wang, X., Wang, L., Wang, J., Jin, P., Liu, H. and Zheng, Y. 2014. Bacillus cereus AR156-induced resistance to Colletotrichum acutatum is associated with priming of defense responses in loquat fruit. PLoS One 9:e112494.

Waqas, M., Khan, A. L., Kamran, M., Hamayun, M., Kang, S. M., Kim, Y. H. and Lee, I. J. 2012. Endophytic fungi produce gibberellins and indoleacetic acid and promotes host-plant growth during stress. Molecules 17:10754-10773.

Weller, D. M. 1988. Biological control of soil borne plant pathogens in the rhizosphere with bacteria. Annu. Rev. Phytopathol. 26:379-407.

Yuan, J., Raza, W., Shen, Q. and Huang, Q. 2012. Antifungal activity of Bacillus amyloliquefaciens NJN-6 volatile compounds against Fusarium oxysporum f. sp. cubense. Appl. Environ. Microbiol. 78:5942-5944. 